NASA TECHNICAL NOTE

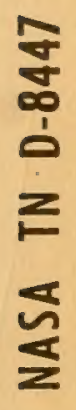
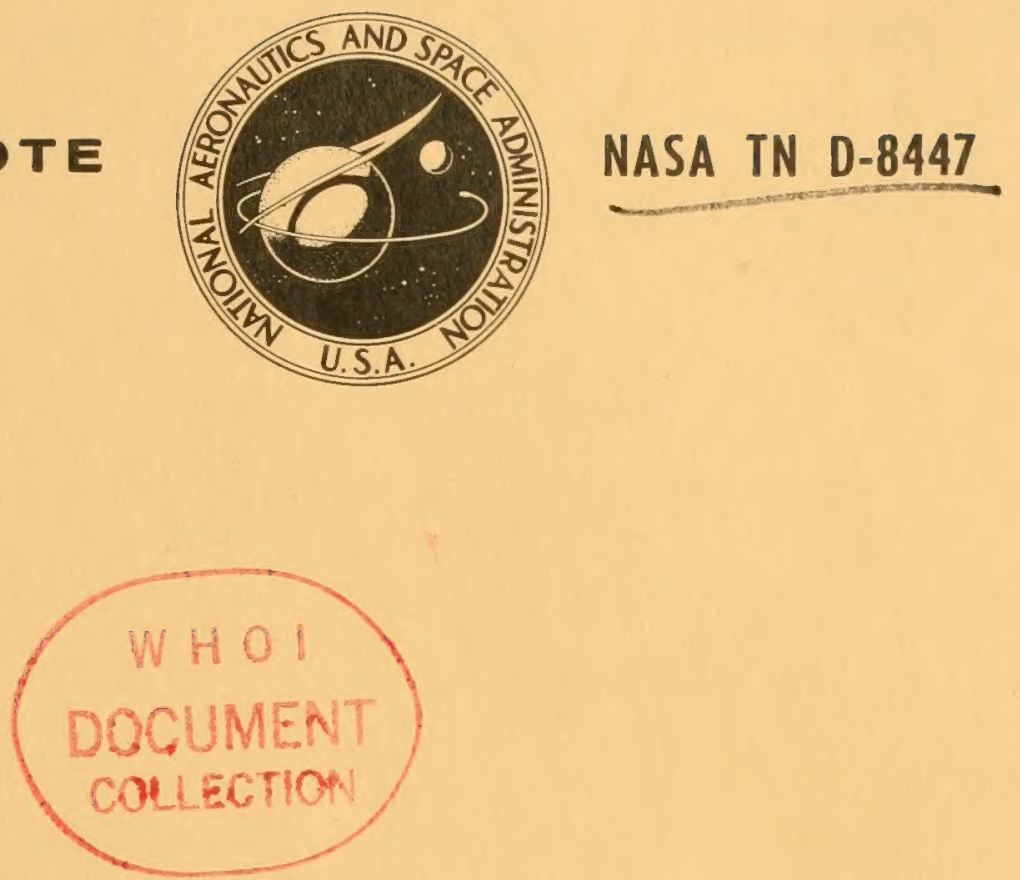

\title{
ANALYSIS OF LASER FLUOROSENSOR SYSTEMS FOR REMOTE ALGAE DETECTION AND QUANTIFICATION
}

Edward V. Browell

Langley Research Center

Hampton, Va. 23665 

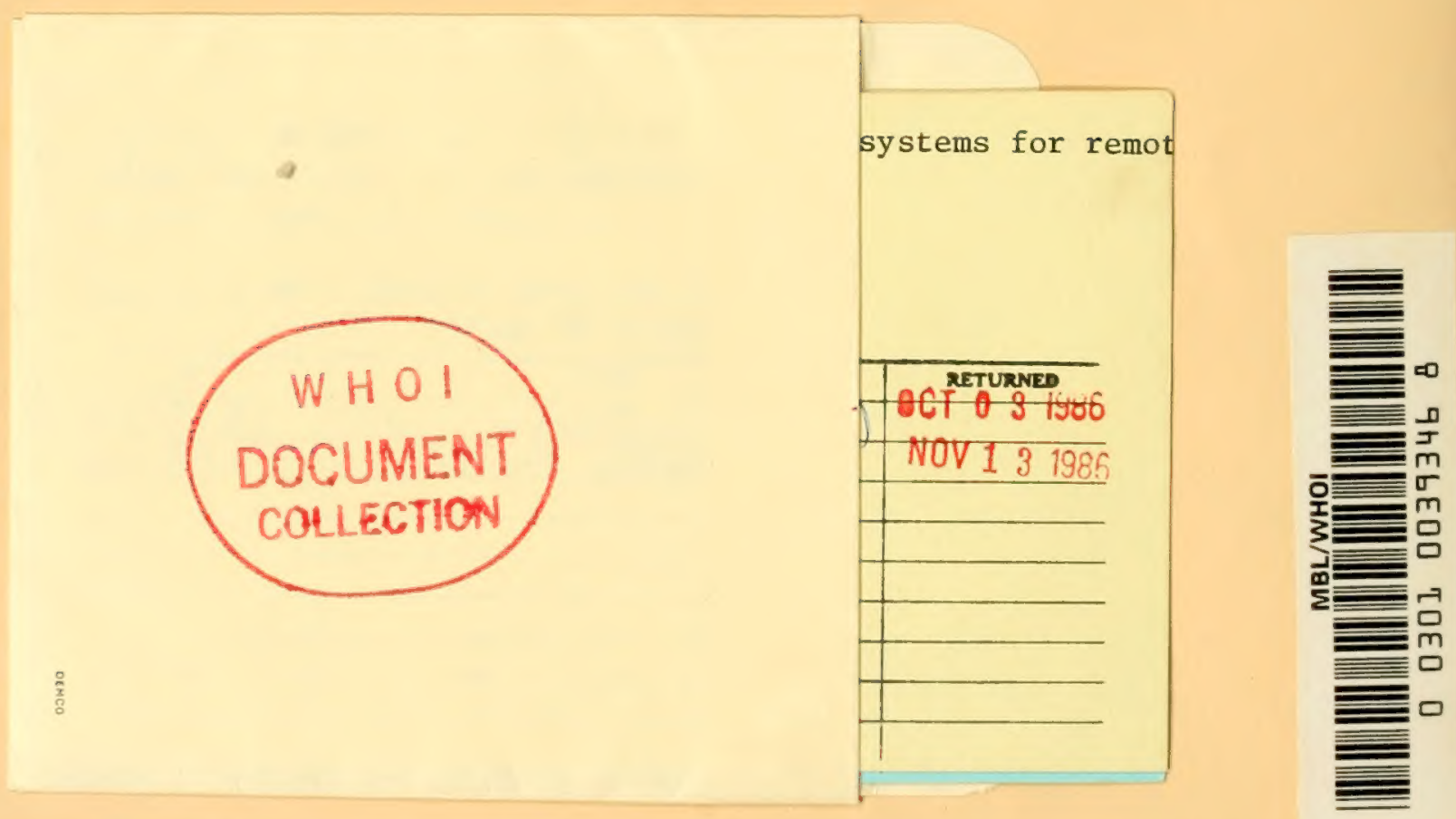


\begin{tabular}{|c|c|}
\hline $\begin{array}{l}\text { 1. Report No. } \\
\text { NASA TN D-8447 }\end{array}$ & 3. Recipient's Catalog No. \\
\hline \multirow{2}{*}{$\begin{array}{l}\text { 4. Title and Subtitle } \\
\text { ANALYSIS OF LASER FLUOROSENSOR SYSTEMS FOR } \\
\text { REMOTE ALGAE DETECTION AND QUANTIFICATION }\end{array}$} & $\begin{array}{l}\text { 5. Repon Date } \\
\text { June } 1977\end{array}$ \\
\hline & 6. Performing Organization Code \\
\hline $\begin{array}{l}\text { 7. Author(s) } \\
\text { Edward V. Browell }\end{array}$ & $\begin{array}{l}\text { 8. Performing Organization Report No. } \\
\text { L-11007 }\end{array}$ \\
\hline \multirow{3}{*}{$\begin{array}{l}\text { 9. Performing Organization Name and Address } \\
\text { NASA Langley Research Center } \\
\text { Hampton, VA } 23665\end{array}$} & $\begin{array}{l}\text { 10. Work Unit No. } \\
176-20-32-07\end{array}$ \\
\hline & 11. Contract or Grant No. \\
\hline & 13. Type of Report and Period Covered \\
\hline $\begin{array}{l}\text { 12. Sponsoring Agency Name and Address } \\
\text { NationaI Aeronautics and Space Administration } \\
\text { Washington, DC } 20546\end{array}$ & $\frac{\text { Technical Note }}{\text { 14. Sponsoring Agency Code }}$ \\
\hline
\end{tabular}

15. Supplementary Notes

16. Abstract

The development and performance of single- and multiple-wavelength laser fluorosensor systems for use in the remote detection and quantification of algae are discussed in this paper. The appropriate equation for the fluorescence power received by a laser fluorosensor system is derived in detail, and the result is found to differ by as much as a factor of 10 from those previously reported in the literature. Experimental development of a single-wavelength system and a four-wavelength system, which selectively excites the algae contained in the four primary algal color groups (green, golden-brown, red, and blue-green), is reviewed, and test results are presented. A comprehensive error analysis is reported which evaluates the uncertainty in the remote determination of the chlorophyll a concentration contained in algae by single- and multiple-wavelength laser fluorosensor systems. Environmental parameters which can greatly affect the fluorescence cross section of algae include long- and short-term light history and nutrient and age effects. Results of the error analysis indicate that the remote quantification of chlorophyll a by a laser fluorosensor system requires optimum excitation wavelength(s), remote measurement of marine attenuation coefficients, and supplemental instrumentation to reduce uncertainties in the algal fluorescence cross sections.

Without these additional measurements, both the single- and multiple-wavelength laser fluorosensor systems can only provide qualitative information about chlorophyll a concentration contained in the algae, and the single-wavelength system will yield results which are comparable to a multiple-wavelength system which has optimum excitation wavelengths.

17. Key Words (Suggested by Author(s))

Laser systems

Remote sensing

Algae detection

Chlorophyl1 a measurement
18. Distribution Statement

Unclassified - Unlimited
19. Security Classif. (of this report) Unclassified
20. Security Classif. (of this page) Unclassified
Subject Category 36 



\title{
ANALYSIS OF LASER FLUOROSENSOR SYSTEMS FOR REMOTE ALGAE
}

\author{
DETECTION AND QUANTIFICATION
}

Edward V. Browell

Langley Research Center

\section{SUMMARY}

The development and performance of single- and multiple-wavelength laser fluorosensor systems for use in the remote detection and quantification of algae are discussed in this paper. The appropriate equation for the fluorescence power received by a laser fluorosensor system is derived in detail, and the result is found to differ by as much as a factor of 10 from those previously reported in the literature. Experimental development of a singlewavelength system and a four-wavelength system, which selectively excites the algae contained in the four primary algal color groups (green, golden-brown, red, and blue-green), is reviewed, and test results are shown. A comprehensive error analysis is reported which evaluates the uncertainty in the remote determination of the chlorophyll a concentration contained in algae by singleand multiple-wavelength laser fluorosensor systems. Environmental parameters which can greatly affect the fluorescence cross section of algae include longand short-term light history and nutrient and age effects. Results of the error analysis indicate that the remote quantification of chlorophyll a by a laser fluorosensor system requires optimum excitation wavelength(s), remote measurement of marine attenuation coefficients, and supplemental instrumentation to reduce uncertainties in the algal fluorescence cross sections. Without these additional measurements, both the single- and multiple-wavelength laser fluorosensor systems can only provide qualitative information about chlorophyll a concentration contained in the algae, and the single-wavelength system yield's results which are comparable to a multiple-wavelength system which has optimum excitation wavelengths.

\section{INTRODUCTION}

An algae laser fluorosensor system consists of a laser, which is used to directly or indirectly excite the chlorophyll a pigment contained in algae, and a collocated telescope receiver system, which detects the emitted fluorescence from chlorophyll a at $685 \mathrm{~nm}$. The quantification of chlorophyll a in vivo (chlorophyll a contained in living algal cells) represents a measure of the concentration and distribution of algae. These measurements are of interest because they are indicative of primary productivity and chemical, thermal, and mechanical conditions in the marine environment.

Passive techniques have been developed to remotely evaluate chlorophyll a in vivo concentration from aircraft and satellites (refs. 1 to 5). These techniques rely on the spectral characteristics of reflected sunlight for determination of the chlorophyll a concentration contained in the algae and, thus, are 
limited to day observations and relatively clear sky conditions. Active remote sensing systems do not have these limitations. A laser fluorosensor system which is operated from a low-altitude aircraft can have day/night operation and can be used when there is high-altitude cloud cover. Because of the rapid surveillance capability of an active system, it can be used for "ground truth" measurements for high-altitude passive instruments and for localized investigations which may require greater spatial resolution than is usually available with passive techniques. Also, a four-wavelength laser fluorosensor system can provide information about the distribution of algae contained in the four algal color groups, whereas current passive techniques do not differentiate between different types of algae.

This paper discusses the importance of algae and algal measurements, the spectral characteristics of algae, and the development of single- and multiplewavelength laser fluorosensor systems. Emphasis is given to a detailed derivation of the equation for the fluorescence power received by a laser fluorosensor system and to the error analysis for determination of chlorophyll a in vivo concentration by single- and multiple-wavelength laser fluorosensor systems.

\section{SYMBOLS}

\begin{tabular}{|c|c|}
\hline A & matrix of elements $a_{i j}$ \\
\hline$A_{r}$ & area of receiving telescope, $\mathrm{m}^{2}$ \\
\hline$A_{z}$ & area illuminated by laser at depth $\mathrm{z}, \mathrm{m}^{2}$ \\
\hline a & water absorption coefficient, $\mathrm{m}^{-1}$ \\
\hline$a_{i j}$ & constants \\
\hline B & diagonal matrix of elements $b_{j j}$ \\
\hline$b_{j j}$ & elements of diagonal matrix such that $\sigma_{i j}=a_{i j} b_{j j}$ \\
\hline $\mathrm{b}$ & water scattering coefficient, $\mathrm{m}^{-1}$ \\
\hline D & telescope diameter, m \\
\hline$F\left(\lambda_{f}\right)$ & $\begin{array}{l}\text { laser-induced fluorescence emitted from chlorophyll a in vivo at } \\
685 \mathrm{~nm}, \mathrm{~W} / \mathrm{nm}\end{array}$ \\
\hline $\mathrm{H}_{\mathrm{Z}}$ & laser irradiance per unit laser wavelength bandwidth, $\mathrm{W} / \mathrm{m}^{2}-\mathrm{nm}$ \\
\hline$k, k_{i}$ & $\left(\gamma_{\ell}+\gamma_{f}\right)$ and $\left(\gamma_{f}+\gamma_{i}\right)$, respectively \\
\hline m & index of refraction for water \\
\hline$N$ & matrix of elements $n_{j}$ \\
\hline
\end{tabular}


concentration of chlorophyll a contained in algae, mole/m 3

$\mathrm{P}_{\mathrm{O}} \quad$ laser output power, $\mathrm{W}$

$\mathrm{P}_{\mathrm{r}} \quad$ power received by detector, $\mathrm{W}$

R distance from laser fluorosensor system to surface of water, $m$

$X \quad$ matrix of elements $x_{i}$

$x_{i} \quad$ defined in equation $(10)$

$\mathrm{z}$ water depth of differential volume under examination, $\mathrm{m}$

$\alpha \quad$ singie-scattering attenuation coefficient, $\mathrm{m}^{-1}$

B atmospheric extinction coefficient, $\mathrm{m}^{-1}$

$\gamma$ effective attenuation coefficient of water, $\mathrm{m}^{-1}$

$\Delta \lambda \quad$ wavelength bandwidth, $\mathrm{nm}$

$\varepsilon_{i j} \quad$ matrix elements of $\Sigma^{-1}$

$\lambda \quad$ wavelength, $\mathrm{nm}$

$\xi \quad$ optical efficiency of receiver system

$\rho \quad$ water surface reflectivity

$\Sigma \quad$ matrix of elements $\sigma_{i j}$

$\sigma \quad$ cross section for fluorescence at $685 \mathrm{~nm}$ per chlorophyll a molecule contained in algae when excited by laser wavelength $\lambda_{\ell}, \mathrm{m}^{2} / \mathrm{mole}$

$\sigma_{i j} \quad=\sigma_{j}\left(\lambda_{i}\right)$

Subscripts:

d detector

f fluorescence, or at fluorescence wavelength, $685 \mathrm{~nm}$

i laser excitation wavelength corresponding to four algal color groups

j four algal color groups

\& laser, or at laser excitation wavelength 
Abbreviations:

ALOPE Airborne Lidar Oceanographic Probing Experiment

PMT photomultiplier tube

A $\delta$ before a symbol denotes the standard deviation of the parameter.

\section{IMPORTANCE OF ALGAE AND ALGAL MEASUREMENTS}

The types and concentration of algae in various bodies of water are important indicators of primary productivity and marine environmental conditions. In the ocean, algae are practically the only producer of organic matter. The photochemical conversion of inorganic matter to organic matter via photosynthesis is known as productivity. Also, algae are an important part of the lowest level on the food chain and are thus important to the survival of all higher forms of marine life.

Marine environmental conditions - such as chemical, thermal, and mechanical factors - can have major influence on algal populations in any body of water. Man-created conditions often upset the natural ecological balance, and this leads to growth in some algal species and death in others. The presence of nondegradable heavy metals, for example, mercury and lead, or slowly degradable chemicals such as DDT, has a dramatic effect on the survivability of different algal species. Likewise, the thermal and mechanical properties of the water which are influenced by electrical power plants, industrial plants, and waste disposal systems, to name only a few, also alter the makeup of algal populations. However, it can be difficult to establish direct effects of a pollution source on algal populations because of changes which are seasonal or locally transient in nature; for example, changes in algal populations can be altered by a sudden weather change.

Several algal species are toxic to fish and man, and when their concentrations reach bloom proportions (typically greater than $10^{6}$ cells/liter), fish are killed. During this condition the shellfish which are affected concentrate the toxin. People who have eaten contaminated shellfish have been known to die from paralytic shellfish poisoning. Gymnodinium breve, the Red Tide of Florida; Gonyaulax tamarensis, the Red Tide of New England; and Gonyaulax catenella, which is found along the California coast, are examples of toxic algae.

Research is necessary to learn more about the parameters which affect the marine ecosystem. Since the type, concentration, and distribution of algae are affected by the chemical, thermal, and mechanical properties of the marine environment, remote detection of algae can be used to infer important information about marine conditions.

\section{SPECTRAL CHARACTERISTICS OF ALGAE}

All optical methods of algae detection employ the spectral properties of the primary light-absorbing pigments, which are present in different algal 
species in different proportions. Most algal species fall into one of four basic color groups - green, golden-brown, red, and blue-green. The color group is determined by the apparent color of the pure algal culture: The spectral characteristics of the primary pigments contained in algae are shown in figure 1 (ref. 6 ). Algal pigments have the following natural colors: chlorophyll $\underline{\mathrm{a}}$ and chlorophyll $\underline{\mathrm{b}}$ are green, carotenoids are orange, phycoerythrin is red, and phycocyanin is blue. All algae contain chlorophyll a ; in addition, green algae contain chlorophyll b, golden-brown algae contain carotenoids and fucoxanthin (not shown in fig. 1), red algae primarily contain phycoerythrin, and blue-green algae primarily contain phycocyanin. There are similarities between the spectral absorption characteristics of the primary pigments and the absorption spectra of algae, as can be seen in figure 2 (ref. 7). As would be expected, the absorption features are not as distinct as those of the individual extracted pigments. This limits the use of specific pigment absorption features in identification of algal species. The primary spectral difference between the green and golden-brown algae is the presence of fucoxanthin in the golden-brown color group. This pigment allows spectral differentiation between these two color groups. Blue-green algae, which are not represented in figure 2, have an absorption spectrum indicative of their primary pigment, phycocyanin.

The exchange of energy between pigments in algae is presented in an elementary form in figure 3. All pigments can absorb appropriate wavelengths of light directly, and the energy is then transferred toward chlorophyll a. Since this process is less than 100-percent efficient for all but chlorophyli $\underline{b}$, some of the energy which is not transferred to the next pigment is lost by nonradiative processes (usually conversion to heat), and the remainder is dissipated as fluorescence by the pigment. The energy reaching chlorophyll a excites it above the first singlet state of the molecule. Energy stored in the chlorophyll a is then used in photosynthesis with any remaining energy dissipated as fluorescence. Since all algae contain chlorophyll a, its fluorescence properties are important for use in active remote sensing techniques. A typical fluorescence spectrum for green and golden-brown algae is shown in figure 4. The primary fluorescence peak at $685 \mathrm{~nm}$ results from deexcitation of the first singlet state of chlorophyll a to the ground state. The secondary peak at $735 \mathrm{~nm}$ is generally lower than the primary peak, and it is a result of a secondary energy exchange mechanism associated with photosynthesis. Red and bluegreen algae also have their primary fluorescence peak at $685 \mathrm{~nm}$. Thus, active remote sensing techniques are based upon detection of the laser-induced fluorescence of chlorophyll a in vivo at $685 \mathrm{~nm}$.

Normalized excitation spectra for representative species of algae in the four primary algal color groups (golden-brown, green, red, and blue-green) are shown in figure 5. In this figure, the fluorescence of chlorophyll a in vivo was monitored at $685 \mathrm{~nm}$ while the wavelength of the excitation light was scanned from $360 \mathrm{~nm}$ to $680 \mathrm{~nm}$ by a Perkin-Elmer fluorescence spectrophotometer. The peaks of the excitation spectra were normalized to a value of 10 for comparison between color groups. Spectrophotometer studies have indicated that these spectra are qualitatively representative of other algal species contained in the same color groups (ref. 8). 


\section{DERIVATION OF POWER RECEIVED BY LASER FLUOROSENSOR SYSTEM}

Unexplained assumptions by many authors (refs. 8 to 14) in deriving the governing equation for the power received by a laser fluorosensor system have resulted in various relationships which differ by as much as a factor of $2 \pi$. A thorough derivation of this equation with justified assumptions is needed to establish the appropriate form of the equation.

The general configuration used in this derivation is given in figure 6. A common assumption in all derivations is that the algae and all scattering material are uniform with depth in the water. The laser irradiance in $\mathrm{W} / \mathrm{m}^{2}-\mathrm{nm}$ which reaches a depth of $z$ in the water is given by

$$
H_{Z}=\frac{P_{0} e^{-\beta_{\ell} R}\left(1-\rho_{\ell}\right) e^{-\gamma_{\ell Z}}}{\Delta \lambda_{\ell} A_{Z}}
$$

where

Po laser output power, $\mathrm{W}$

Bl

atmospheric extinction coefficient at laser wavelength, $\mathrm{m}^{-1}$

$\mathrm{R}$

distance from laser fluorescence system to water, m

$P_{\ell}$ water surface reflectivity at laser wavelength

$Y_{\ell}$ effective attenuation coefficient of water at laser wavelength, $\mathrm{m}^{-1}$

Z water depth of differential volume under examination, $m$

$\Delta \lambda_{\ell}$ wavelength bandwidth of laser energy, $\mathrm{nm}$

$\mathrm{A}_{\mathrm{Z}}$ area illuminated by laser at a depth of $\mathrm{z}, \mathrm{m}^{2}$

The effective water attenuation coefficient may vary with depth (ref. 15) because of changes in the angular distribution of laser light as it is multiply scattered and deviated from collimated light at the surface to relatively diffuse light several attenuation lengths underwater (ref. 16). The singlescattering attenuation coefficient for a collimated beam is

$$
\alpha=a+b
$$

where $a$ is the absorption coefficient and $b$ is the scattering coefficient. It is assumed in the derivation of $\alpha$ that if a photon is scattered it is lost to the beam, and the energy in the unscattered beam is exponentially reduced by the amount $e^{-\alpha r}$ where $r$ is the distance traveled in the water (ref. 16). Since the laser excitation wavelengths for algae are between 400 and $650 \mathrm{~nm}$, 
the scattering coefficient is, in general, many times larger than the absorption coefficient (ref. 17). The irradiance at depth $z$ includes unscattered and scattered light. The effective attenuation coefficient is then less than $\alpha$ because the scattered light is mostly forward scattered (ref. 18), and thus it can also become part of the irradiance at depth $z$. The diffuse attenuation coefficient determines the exponential attenuation of diffuse light with depth. Duntley (ref. 19) empirically determined that the diffuse attenuation coefficient $k$ is

$$
k=a+\frac{b}{6}
$$

Because of the large contribution of scattered light to the irradiance of the laser light, the effective attenuation coefficient for laser penetration $\gamma_{\ell}$ is better approximated by the diffuse attenuation coefficient $k_{\ell}$ at the laser wavelength than by the single-scattering attenuation coefficient. The limiting value of $\gamma_{\ell}$ is al for very large collection cone angles, that is, greater than $40^{\circ}$ (ref. 20); however, this extreme value for the effective attenuation coefficient is not felt to be generally applicable for most laser irradiance cases. In this analysis it is assumed that $\gamma$ is constant with depth. It should be noted that Koeppen and Walker (ref. 15) have reported that $\gamma$ may change with depth; however, no generalized relationship was given for this variation.

The laser-induced $\mathrm{fluorescence,} \mathrm{in} \mathrm{W} / \mathrm{nm}$, emitted from the chlorophyll a in vivo at $685 \mathrm{~nm}$ contained in the differential volume $A_{z} d z$ at a depth of $z$ is

$$
\mathrm{dF}\left(\lambda_{\mathrm{f}}\right) \Delta \lambda_{\mathrm{f}}=\mathrm{H}_{\mathrm{z}} \Delta \lambda_{\ell} \text { on } A_{\mathrm{z}} \mathrm{dz}
$$

where

$\Delta \lambda_{\mathrm{f}} \quad$ fluorescence bandwidth at $685 \mathrm{~nm}, \mathrm{~nm}$

$\sigma$

cross section for fluorescence at $685 \mathrm{~nm}$ per chlorophyl1 a molecule contained in the algae when excited by laser wavelength $\lambda_{\ell}$, $\mathrm{m}^{2} /$ molecule

n

concentration of chlorophyll a contained in the algae, molecule/m 3

The fluorescence cross section per chlorophyll a molecule is equal to the fluorescence energy emitted per chlorophyll a molecule at $685 \mathrm{~nm}$ divided by the incident excitation energy per unit area.

The fluorescence which is emitted from the volume $A_{z} d z$ in the direction of the laser fluorosensor system is refracted at the water surface. Thus, the criterion for fluorescence to be collected by the telescope receiver system is 


$$
z \tan \theta+R \tan \theta^{\prime} \leqq \frac{D}{2}
$$

where $\theta$ is the angle of the fluorescence emitted from the volume $A_{z} d z$ measured from the vertical, $\theta^{\prime}$ is the angle of the fluorescence after refraction at the water surface, and $D$, the telescope diameter, is equal to $\sqrt{4 A_{r} / \pi}$ where $A_{r}$ is the area of the receiving telescope. By using Snell's Law and assuming that $\theta$ and $\theta^{\prime}$ are small angles, the previous criterion becomes

$$
\theta \leqq \frac{D}{2(z+m R)}
$$

where $m$ is the index of refraction for water. The fluorescence which is emitted from the volume $A_{z} d z$ into the solid angle $\pi(z \theta)^{2} / z^{2}$ is collected by the telescope receiver system. Based on the limiting values for $\theta$, the maximum value of the collection solid angle is $A_{r} /(z+m R)^{2}$. Since the fluorescence from the volume $A_{z} d z$ is emitted into $4 \pi$ steradians, the fractional proportion of emitted fluorescence to be collected by the telescope is $A_{r} / 4 \pi(z+m R)^{2}$. Thus, the differential power received at the detector in the laser fluorosensor system with the field of view of the receiver large enough to accept the fluorescence emitted from the algae contained in the volume $A_{z} d z$ is

$$
d P_{r}=d F\left(\lambda_{f}\right) \frac{A_{r}}{4 \pi(z+m R)^{2}} e^{-\gamma_{f} z}\left(1-\rho_{f}\right) e^{-\beta_{f} R_{\xi}} \Delta \lambda_{d}
$$

where

$\gamma_{\mathrm{f}} \quad$ effective attenuation coefficient of water at $685 \mathrm{~nm}, \mathrm{~m}^{-1}$

of water surface reflectivity at $685 \mathrm{~nm}$

Bf atmospheric extinction coefficient at $685 \mathrm{~nm}, \mathrm{~m}^{-1}$

$\xi \quad$ optical efficiency of receiver system

$\Delta \lambda_{\mathrm{d}} \quad$ receiver wavelength bandwidth, $\mathrm{nm}$

Since the absorption coefficient $a$ is in general larger than the scattering coefficient b at $685 \mathrm{~nm}$ for a wide range of water turbidity (ref. 17), the effective attenuation coefficient for the fluorescence $\gamma_{f}$ is dominated by $a$. The form of $\gamma_{\mathrm{f}}$ is

$$
\gamma_{f}=a_{f}+\frac{b_{f}}{c}
$$


where $c$ can range from 1 to 6 depending upon the ratio $a / b$. For example, if $a / b>2$, $c$ may be in the range $1<c<3$, and if $a / b<1 / 3$, $c$ may range from $3<c<6$. With most of the fluorescence power reaching, the receiver being emitted within two attenuation lengths of the surface and with $\mathrm{a}>\mathrm{b}$ for most cases, the optical depth due to scattering is less than 1. From data presented in reference 18 on the propagation of light from a spherical lamp, it can be reasoned that for scattering optical depths less than 1 the value of $c$ falls in the range $1<c<2$. Since the effective attenuation coefficient varies with depth and turbidity, its form can only be roughly approximated by

$$
\gamma_{f} \approx a_{f}+\frac{b_{f}}{1.5}
$$

Combining equations (1), (2), and (3) yields

$$
d P_{r}=K \frac{e^{-\left(\gamma_{\ell}+\gamma_{f}\right) z}}{(z+m R)^{2}} d z
$$

where

$$
K=\frac{P_{o} \xi A_{r} \Delta \lambda_{d}\left(1-\rho_{\ell}\right)\left(1-\rho_{f}\right) e^{-\left(\beta_{\ell}+\beta_{f}\right) R_{\sigma n}}}{4 \pi \Delta \lambda_{f}}
$$

The total power received by the telescope is obtained by integration of $\mathrm{dP}_{r}$ over all values of $\mathrm{z}$. Thus,

$$
P_{r}=K \int_{0}^{\infty} \frac{e^{-\left(\gamma_{\ell}+\gamma_{f}\right) z}}{(z+m R)^{2}} d z
$$

Making the transformation $w=\frac{m R+z}{m R}$ yields

$$
P_{r}=\frac{K}{m R} e^{\left(\gamma_{\ell}+\gamma_{f}\right) m R} \int_{1}^{\infty} \frac{e^{-\left(\gamma_{\ell}+\gamma_{f}\right) m R w}}{w^{2}} d w
$$


By using the definition for a second-order exponential integral,

$$
E_{2}(x)=\int_{1}^{\infty} \frac{e^{-x y}}{y^{2}} d y
$$

(eq. 5.1 .4 of ref. 21) and the recurrence relationship,

$$
E_{2}(x)=e^{-x}-x E_{1}(x)
$$

(eq. 5.1 .14 of ref. 21), the power received equation can be written as

$$
P_{r}=\frac{K}{m R}\left\{1-\left(\gamma_{\ell}+\gamma_{f}\right) m R e^{\left(\gamma_{\ell}+\gamma_{f}\right) m R} E_{1}\left[\left(\gamma_{\ell}+\gamma_{f}\right) m R\right]\right\}
$$

Since the smallest values for the effective attenuation coefficients are the respective absorption coefficients, $a_{f}=0.45 \mathrm{~m}^{-1}$ at $685 \mathrm{~nm}$ and $a_{\ell}>0.05 \mathrm{~m}^{-1}$ between $400 \mathrm{~nm} \leqq \lambda_{\ell} \leqq 650 \mathrm{~nm}$ (ref. 17). Thus, the value of $\gamma_{\ell}+\gamma_{f}$ must be greater than $0.50 \mathrm{~m}^{-1}$, and since $\mathrm{m} \approx 1.33$ and $\mathrm{R} \geqq 100 \mathrm{~m}$ for most cases, $\left(\gamma_{\ell}+\gamma_{f}\right) m R \geqq 66$. The functional representation for $E_{1}(x)$ can be shown to be approximated with less than 0.1-percent error by the first two terms in its asymptotic expansion,

$$
E_{1}(x) \approx \frac{e^{-x}}{x}\left(1-\frac{1}{x}\right)
$$

when $x \geqq 66$ (eq. 5.1.51 and table 5.2 of ref. 21). Substitution of this approximation into equation (5) yields the following general equation for the fluorescence power detected by the laser fluorosensor system:

$$
P_{r}=\frac{P_{0} \xi A_{r} \Delta \lambda_{d}\left(1-\rho_{\ell}\right)\left(1-\rho_{f}\right) e^{-\left(\beta_{\ell}+\beta_{f}\right) R} \sigma n}{4 \pi \Delta \lambda_{f}\left(\gamma_{\ell}+\gamma_{f}\right) m^{2} R^{2}}
$$

The uncertainty discussed previously in specifying the values of $\gamma_{\ell}$ and $\gamma_{f}$ makes the small correction factors for surface reflectivity and atmospheric attenuation for ranges less than $1 \mathrm{~km}$ negligible. Thus, the simplified form of the power received is 


$$
P_{r}=\frac{P_{0} \xi A_{r} \Delta \lambda_{d} \sigma n}{4 \pi \Delta \lambda_{f}\left(\gamma_{\ell}+\gamma_{f}\right) m^{2} R^{2}}
$$

where the approximations for $\gamma_{\ell}$ and $\gamma_{f}$ are $\gamma_{\ell} \approx a_{\ell}+b_{\ell} / 6$ and $\gamma_{f} \approx a_{f}+b_{f} / 1.5$. With laser excitation wavelength in the range $400 \mathrm{~nm} \leqq \lambda_{l} \leqq 650 \mathrm{~nm}$ and with $\lambda_{\mathrm{f}}=685 \mathrm{~nm}$, the value of $\gamma_{\mathrm{f}}$ is more than 2 times the value of $Y_{\ell}$ determined from the data taken from Vineyard Sound (ref. 22) and Chesapeake Bay (ref. 23). The equations given in references 8 to 14 for the power received by a laser fluorosensor system range from a factor of $2 \pi \mathrm{m}^{2}$ larger to a factor of $\gamma$ less than equation (6). Equation (6) is felt to be the correct representation of the power received, and the concentration of chlorophyll a in vivo can be obtained by solving for $n$ in equation (6). Thus,

$$
n=\frac{P_{r} 4 \pi \Delta \lambda_{f}\left(\gamma_{\ell}+\gamma_{f}\right) m^{2} R^{2}}{P_{o} \xi A_{r} \Delta \lambda_{d} \sigma}
$$

This is the basic relationship used with all single- and multiple-wavelength laser fluorosensor systems for determination of chlorophyll a in vivo concentrations.

\section{SINGLE-WAVELENGTH LASER FLUOROSENSOR SYSTEMS}

The first laboratory tests involving laser-induced fluorescence of algae were conducted by Hickman and Moore (ref. 9) in 1970 using a nitrogen laser operating at $337 \mathrm{~nm}$ and two algal species, Anacystis nidulans (a blue-green algae) and Chlorella pyrenoidosa (a green algae). The fluorescence of chlorophyll a contained in the algae was detected at $680 \mathrm{~nm}$. Laboratory experiments revealed that laser-induced fluorescence from a chlorophyll a concentration of $6 \mu \mathrm{g} /$ liter which was contained in Anacystis nidulans was remotely detectable from less than $1 \mathrm{~m}$. Projections of these measurements suggested that an airborne laser/receiver system could detect these same concentrations of chlorophyll a in vivo from a distance of $100 \mathrm{~m}$. Friedman and Hickman (ref. 10) were the first to state that various algal species could be identified by detection of their fluorescence signatures using a tunable laser as the excitation source. They concluded that if only chlorophyll a in vivo is of interest, the optimum excitation wavelength is $600 \pm 50 \mathrm{~nm}$ and the optimum detection wavelength is $685 \mathrm{~nm}$. Measurement of concentrations as low as $1 \mathrm{\mu g} / \mathrm{liter}$ for chlorophyll a in vivo from a distance of $500 \mathrm{~m}$ using a 100-kW peak power laser was calculatè to be feasible.

The first field test of a single-wavelength laser system for the detection of chlorophyll a contained in algae was conducted in December of 1971 by Mumola and Kim (ref. 1 $1 \overline{1}$ ) from a fixed platform on the Thimble Shoals Channel Pier of the Chesapeake Bay Bridge Tunnel. A coaxial, flash-lamp-pumped, rhodamine 6G dye laser was used as the excitation source, and a 15-cm-diameter telescope, 
with a narrow band-pass filter which was centered at $685 \mathrm{~nm}$, was used as the receiver. Results from this field trip are shown in figure 7. Chlorophyll a in vivo concentrations were determined at 1-hour intervals over a 24-hour period. In situ data (data obtained by analyzing samples taken from the water) were supplied by the Environmental Protection Agency (EPA). The fluorescence signals were normalized to EPA findings at 2000 EST on December 29, 1971. The results of this experiment were encouraging, and subsequent helicopter flight experiments were conducted near Wallops Island, Virginia. However, these flight experiments resulted in only limited success.

Using the same basic laser system which was used in field tests over the Chesapeake Bay, Kim (ref. 12) flew the instrument in a helicopter over Lake Ontario at the request of EPA. A transect was made of Lake Ontario from west of Rochester, New York, to the Canadian shore at an altitude of $30 \mathrm{~m}$. The remotely sensed chlorophyll a in vivo concentrations were found to be 50 percent higher along the United States side than in midlake or on the Canadian side. The results of this flight are presented in figure 8 . No sea truth measurements were reported for this experiment. One of the primary drawbacks of the single-wavelength laser system was its inability to account for differences in absorption by various pigments contained in different algal color groups. Thus, the laser system would not be able to accurately determine chlorophyll a in vivo concentrations if the mixture of algal types changed over the flight path. Also, any change in the light scattering properties of the water during the flight would also produce errors in the calculated values for chlorophyll a in vivo concentrations.

\section{MULTIPLE-WAVELENGTH LASER FLUOROSENSOR SYSTEM}

A four-color airborne fluorosensor (ALOPE - Airborne Lidar Oceanographic Probing Experiment) was developed at NASA Langley Research Center (refs. 8, 13, and 14) for determining the distribution and chlorophyll a in vivo concentrations of the four primary algal color groups. The laser excitation wavelengths used for the golden-brown, green, red, and blue-green color groups were 454, 539, 598, and $618 \mathrm{~nm}$, respectively. These were the most optimized laser wavelengths which could be obtained with the low-gain laser design used in the ALOPE system. A single linear flash lamp is used to simultaneously pump four dye cells symmetrically spaced about the flash lamp, and a rotating aperture permitted lasing from only one dye laser cavity at a time. The ALOPE system is shown schematically in figure 9. A system of bending mirrors directs the laser light coaxial with the 25.4-cm-diameter telescope receiving system. The fluorescence of the chlorophyll a in vivo is collected by the telescope system, which passes only light at $6 \overline{8} 5 \mathrm{~nm}$.

By assuming uniform vertical distribution of turbidity and chlorophyll a in vivo concentration in the water, a set of four coupled equations results from summing the fluorescence contribution to the power received by the laser fluorosensor system from each algal color group for each laser excitation wavelength. The pertinent equations, derived from equation (6), are 


$$
P_{r}\left(\lambda_{i}\right)=\frac{P_{o}\left(\lambda_{i}\right) \xi A_{r} \Delta \lambda_{d}}{4 \pi\left(\gamma_{f}+\gamma_{i}\right) m^{2} R^{2} \Delta \lambda_{f}} \sum_{j=1}^{4} \sigma_{j}\left(\lambda_{i}\right) n_{j} \quad(i=1,2,3,4)
$$

where subscript $i$ denotes the laser excitation wavelength, and subscript $j$ denotes the algal color group. It should be noted that these equations are different from the equations derived in references 8, 13, and 14 (which are all by the same authors) for a multiple-wavelength laser fluorosensor system. The matrix elements for equation ( 8 ) can be written as

$$
x_{i}=\sum_{j=1}^{4} \sigma_{i j n_{j}} \quad(i=1,2,3,4)
$$

where

$$
x_{i}=\frac{P_{r}\left(\lambda_{i}\right)}{P_{0}\left(\lambda_{i}\right)} \frac{4 \pi\left(\gamma_{f}+\gamma_{i}\right) m^{2} R^{2} \Delta \lambda_{f}}{\xi_{A_{r}} \Delta \lambda_{d}}
$$

and

$$
\sigma_{i j}=\sigma_{j}\left(\lambda_{i}\right)
$$

Thus the matrix form of equation ( 8 ) is

$$
X=\sum N
$$

The concentration matrix $\mathrm{N}$ can then be determined from

$$
N=\Sigma^{-1} X
$$

where $\Sigma^{-1}$ is the inverse matrix of $\Sigma$. The matrix derivation of equation (11) is similar to that given in references 8,13 , and 14. In order for the concentrations of chlorophyll a for each algal color group to be determined from equation (11), the fluorescence cross sections of the algae $\sigma_{j}\left(\lambda_{i}\right)$ must be known for each measurement, and the parameters $P_{r}\left(\lambda_{i}\right), P_{0}\left(\lambda_{i}\right), \gamma_{f}$, and $\gamma_{i}$ must be determined for each laser firing. In the initial experiments which were conducted with the ALOPE system, only the power received by the detection system $P_{r}\left(\lambda_{i}\right)$ was recorded for each laser shot. It was assumed that the power output of each laser was predictable and that the attenuation coefficients $\gamma_{f}$ and $\gamma_{i}$ would be determined by in situ measurement techniques.

The first field test of the ALOPE system was conducted from the George P. Coleman Bridge $30 \mathrm{~m}$ above the surface of the York River at Yorktown, Virginia. 
Ground truth data for chlorophyll a in vivo concentrations, salinity, and algal species identification were supplied by the Virginia Institute of Marine Sciences (VIMS), and water temperature and attenuation coefficients were measured for each test. The results from that test are shown in figure 10 (ref. 8). Because of ambiguous data obtained at the laser wavelengths of $598 \mathrm{~nm}$ and $618 \mathrm{~nm}$, only results obtained at the laser wavelengths of $454 \mathrm{~nm}$ and $539 \mathrm{~nm}$, which corresponded to optimum excitation of green and golden-brown algae, were used to determine the total chlorophyll a concentration given in the figure. The calculation was made according to a matrix equation (ref. 13) which was similar to equation (11). However, the constant in the powerreceived equation in reference 13 is a factor of 2 larger than equation (8), and reference 13 defines $\gamma_{f}$ and $\gamma_{i}$ as the single-scattering attenuation coefficients $\alpha_{f}$ and $\alpha_{i}$. Since $\gamma_{f}$ and $\gamma_{i}$, as defined previously, are always less than $\alpha_{f}$ and $\alpha_{i}$, the value of $P_{r}\left(\lambda_{i}\right)$ would be smaller because of the single-scattering attenuation coefficient assumption. Thus the errors in the analysis of ALOPE data were somewhat offsetting, and the results which were obtained were encouraging enough so that the instrument was subsequently flown over the lower end of the James River in Virginia. Figure 11 shows the flight path of the helicopter on the 138-km flight. The distance from the laser system to the water was approximately $100 \mathrm{~m}$, and, as a result of a 2-second interval between each of the four laser firings, one complete data set was obtained over each 270 meters. The averages of the remotely sensed chlorophyll a concentrations, calculated from the power-received equation in references 8 and 14 were obtained for each leg of the flight and are presented only for information in figures 11 and 12 . (The error bars represent differences between outgoing and incoming legs of the flight.) Note the $2 \pi m^{2}$ difference between equation ( 8 ) and the power-received equation in references 8 and 14 and also note attenuation coefficient definition differences. In addition, it should be mentioned that the data obtained with the rhodamine 6G laser, which operates at $598 \mathrm{~nm}$, were not used because of filter blocking problems and because ground truth measurements indicated that there were no red algae present in the water. The fluorescence cross sections given in reference 14 were used in the data reduction, and attenuation coefficients were obtained from in situ measurements over the flight path of the helicopter. No comparison of these results with in situ measurements of chlorophyll a concentrations was reported. The calculated concentrations of chlorophyll $\bar{a}$ in each algal color group can only be expected to predict the actual concentrations when the proper relationship, as given in equation ( 8 ), is used to relate the fluorescence power received by the laser fluorosensor system to the chlorophyll a concentration in the water.

\section{ERROR ANALYSIS OF LASER FLUOROSENSOR SYSTEMS}

\section{Single-Wavelength Systems}

The chlorophyll a in vivo concentration is determined for a singlewavelength laser fluorosensor system by equation (7). To find the statistical variance of the chlorophyll a in vivo concentration, it is first assumed that $P_{0}, P_{r}, \quad\left(\gamma_{\ell}+\gamma_{f}\right)$, and $\sigma$ are independent random variables and the other parameters in the equation are constants. The general variance equation, which is based upon propagation of errors by least squares (ref. 24), is given by 


$$
(\delta f)^{2}=\sum_{i=1}^{n}\left(\left.\frac{\partial f}{\partial u_{i}}\right|_{u_{1}, u_{2}, u_{3}, u_{4}}\right)^{2}\left(\delta u_{i}\right)^{2}
$$

where $\delta f$ is the standard deviation and $(\delta f)^{2}$ is the variance of the function $f$ which has $n$ independent variables $u_{i} ; \delta u_{j}$ is the standard deviation and $\left(\delta u_{i}\right)^{2}$ is the variance of $u_{i}$. It can be readily shown that from equation (7) the following variance relationship exists:

$$
\left(\frac{\delta \mathrm{n}}{\mathrm{n}}\right)^{2}=\left(\frac{\delta \mathrm{P}_{\mathrm{r}}}{\mathrm{P}_{\mathrm{r}}}\right)^{2}+\left(\frac{\delta \mathrm{P}_{0}}{\mathrm{P}_{\mathrm{o}}}\right)^{2}+\left(\frac{\delta \sigma}{\sigma}\right)^{2}+\left(\frac{\delta \mathrm{k}}{\mathrm{k}}\right)^{2}
$$

where $k=\gamma_{l}+\gamma_{f}$. The normalized variance of each of the variables thus contributes equally to the normalized variance of the chlorophyll a in vivo concentration. Table 1 contains example solutions of equation (13). It can be seen that the variable with the largest normalized standard deviation dominates the normalized standard deviation for the chlorophyll a concentration. Since power measurements can be made to an accuracy of 2.5 percent, the concentration error is due mostly to uncertainties in fluorescence cross section and effective attenuation coefficient. The expected magnitude of these uncertainties is discussed in a subsequent section.

\section{Multiple-Wavelength Systems}

Two different approaches to the error analysis for a multiple-wavelength system are used. In the first approach, all of the fluorescence cross sections $\sigma_{j}\left(\lambda_{i}\right)$ in equation (8) are considered independent variables. The second approach assumes that the fluorescence cross sections for each algal color group always have the same relative magnitude and vary only in absolute magnitude.

First approach. - The variance equation which is based upon the first approach can be derived from equation (9) by using the inverse matrix $\Sigma^{-1}$ defined in equation (11) and the general variance equation defined in equation (12). The derivation of the variance equation for chlorophyll a concentration (private communication from R. T. Thompson, Jr., Old Dominion University, Norfolk, Virginia) results in the following relationship:

$$
\left(\delta_{n_{j}}\right)^{2}=\sum_{m=1}^{4}\left[\left(\varepsilon_{j m}\right)^{2}\left(\delta x_{m}\right)^{2}+\sum_{i=1}^{4}\left(\varepsilon_{j m} n_{i}\right)^{2}\left(\delta \sigma_{m i}\right)^{2}\right]
$$

where $\varepsilon_{j m}$ are the elements $\Sigma^{-1}$ and the other parameters are the same as those previously defined in deriving equation (11). The normalized form of this equation is 


$$
\left(\frac{\delta n_{j}}{n_{j}}\right)^{2}=\frac{1}{n_{j}^{2}} \sum_{m=1}^{4}\left(\varepsilon_{j m} x_{m}\right)^{2}\left(\frac{\delta x_{m}}{x_{m}}\right)^{2}+\frac{1}{n_{j}^{2}} \sum_{m=1}^{4} \sum_{i=1}^{4}\left(\varepsilon_{j m} \sigma_{m i} n_{i}\right)^{2}\left(\frac{\delta \sigma_{m i}}{\sigma_{m i}}\right)^{2}
$$

The definition of $x_{i}$ (eq. (10)) and the general variance equation (12) can be readily used to show

$$
\left(\frac{\delta x_{i}}{x_{i}}\right)^{2}=\left[\frac{\delta P_{r}\left(\lambda_{i}\right)}{P_{r}\left(\lambda_{i}\right)}\right]^{2}+\left[\frac{\delta P_{0}\left(\lambda_{i}\right)}{P_{0}\left(\lambda_{i}\right)}\right]^{2}+\left(\frac{\delta k_{i}}{k_{i}}\right)^{2}
$$

where $k_{i}=\gamma_{f}+\gamma_{i}$. For the present discussions the subscripts are dropped from the normalized variances (e.g., $\delta \sigma_{\mathrm{mi}} / \sigma_{\mathrm{mi}}=\delta \sigma / \sigma$ for $\mathrm{m}=1,2,3,4$ and $i=1,2,3,4)$. Equations (14) and (15) then become

$$
\left(\frac{\delta n_{j}}{n_{j}}\right)^{2}=\left[\frac{1}{n_{j}^{2}} \sum_{m=1}^{4}\left(\varepsilon_{j m} x_{m}\right)^{2}\right]\left(\frac{\delta x}{x}\right)^{2}+\left[\frac{1}{n_{j}^{2}} \sum_{m=1}^{4} \sum_{i=1}^{4}\left(\varepsilon_{j m} \sigma_{m i} n_{i}\right)^{2}\right]\left(\frac{\delta \sigma}{\sigma}\right)^{2}
$$

and

$$
\left(\frac{\delta x}{x}\right)^{2}=\left(\frac{\delta P_{r}}{P_{r}}\right)^{2}+\left(\frac{\delta P_{0}}{P_{0}}\right)^{2}+\left(\frac{\delta k}{k}\right)^{2}
$$

These equations were evaluated for two cases. In case I, the calculated normalized variance for the chlorophyll a concentration was based upon the laser excitation wavelengths and fluorescence cross sections which are used in the ALOPE system (ref. 14) and are shown in table 2. In case II, a set of optimized laser wavelengths were visually chosen from figure 5 so that the difference between each algal color group and the other three would be maximized. The fluorescence cross sections for each algal color group at each laser wavelength were obtained from the data presented for representative algal species in figure 5 of reference 14. Table 3 lists these parameters. No consideration was given to the practicality of using lasers which operate at these wavelengths; however, all wavelengths throughout the visible spectrum can be obtained with high gain dye lasers. For both cases I and II it was assumed that there was a mean concentration of $20 \mu \mathrm{g} /$ liter of chlorophyll a in vivo in all algal color groups present in the water, and the power received for each excitation wavelength was calculated from equation (8) using the following laser fluorosensor system parameters from reference 14:

$$
\begin{aligned}
& \xi=0.25 \\
& A_{r}=0.05 \mathrm{~m}^{2}
\end{aligned}
$$




$$
\begin{aligned}
& R=100 \mathrm{~m} \\
& \Delta \lambda_{d}=5 \mathrm{~nm} \\
& \Delta \lambda_{f}=20 \mathrm{~nm} \\
& P_{o}\left(\lambda_{i}\right)=5000 \mathrm{~W} \text { (peak power at each laser excitation wavelength } \lambda_{i} \text { ) }
\end{aligned}
$$

The normalized standard deviation for the chlorophyll a concentration for cases I and II was determined from equations (16) and (17) for various values of the normalized standard deviations of $P_{r}, P_{O}, k$, and $\sigma$. These results are shown in table 4.

Second approach.- In the second approach to the error analysis of the chlorophyll a concentration, it is assumed that the ratios between the fluorescence cross sections at the four excitation wavelengths for each algal color group are constant and only the absolute magnitude of the fluorescence cross sections can change. With these assumptions, equation (9) can be reduced to

$$
x_{i}=\sum_{j=1}^{4} a_{i j} b_{j j^{n}}
$$

where $\sigma_{i j}=a_{i j} b_{j j}$ and $a_{i j}$ are constants. In matrix form this may be written

$$
X=A B N
$$

where $B$ is a diagonal matrix and $A$ is a matrix of constants. Taking a derivative of both sides and using the chain rule results in the following equation:

$$
X^{\prime}=A B^{\prime} N+A B N^{\prime}
$$

By using matrix algebra, $\mathbb{N}^{\prime}$ can be determined from

$$
N^{\prime}=B^{-1} A^{-1} X^{\prime}-B^{-1} B^{\prime} N
$$

where $A^{-1}$ and $B^{-1}$ are the inverse matrices for $A$ and $B$. It can also be shown that $B^{-1} A^{-1}=\Sigma^{-1}$ where $\Sigma^{-1}$ was previously defined. In terms of matrix elements equation $(18)$ can be written 


$$
d n_{j}=\sum_{m=1}^{4} \varepsilon_{j m} d x_{m}-\frac{1}{b_{j j}} d b_{j j} n_{j}
$$

where $\varepsilon_{j m}$ are the matrix elements of $\Sigma^{-1}$, and since $B$ is a diagonal matrix, $\mathrm{B}^{-1}$ is a diagonal matrix and has as its matrix elements $1 / \mathrm{b}_{j j}$. From this equation the following partial derivatives can be obtained:

$$
\frac{\partial n_{j}}{\partial x_{m}}=\varepsilon_{j m}
$$

and

$$
\frac{\partial n_{j}}{\partial b_{j j}}=-\frac{n_{j}}{b_{j j}}
$$

Substitution of these relationships into the general variance equation (12) yields

$$
\left(\delta n_{j}\right)^{2}=\sum_{m=1}^{4}\left(\varepsilon_{j m}\right)^{2}\left(\delta x_{m}\right)^{2}+\left(\frac{n_{j}}{b_{j j}}\right)^{2}\left(\delta b_{j j}\right)^{2}
$$

The normalized form of this equation becomes

$$
\left(\frac{\delta n_{j}}{n_{j}}\right)^{2}=\frac{1}{n_{j}^{2}} \sum_{m=1}^{4}\left(\varepsilon_{j m} x_{m}\right)^{2}\left(\frac{\delta x_{m}}{x_{m}}\right)^{2}+\left(\frac{\delta \sigma_{i j}}{\sigma_{i j}}\right)^{2}
$$

where

$$
\left(\frac{\delta \sigma_{i j}}{\sigma_{i j}}\right)^{2}=\left(\frac{\delta b_{j j}}{b_{j j}}\right)^{2}
$$

and

$$
\left(\frac{\delta \mathrm{x}_{\mathrm{m}}}{\mathrm{x}_{\mathrm{m}}}\right)^{2}=\left(\frac{\delta \mathrm{P}_{0}}{\mathrm{P}_{\mathrm{o}}}\right)^{2}+\left(\frac{\delta \mathrm{P}_{\mathrm{r}}}{\mathrm{P}_{\mathrm{r}}}\right)^{2}+\left(\frac{\delta \mathrm{k}}{\mathrm{k}}\right)^{2}
$$


The first term on the right side of equation (19) is the same as that in equation (14). This would be expected because the only difference in the two approaches was in the statistics dealing with the fluorescence cross sections and not the $x_{i}$ parameters. The variance of the normalized chlorophyll a concentration contained in an algal color group is dependent upon the variance in the normalized fluorescence cross section at any excitation wavelength of the same algal color group. Results of calculations of $\delta n_{j} / n_{j}$ from equation (19) for cases I and II are given in table 5. It is assumed that the normalized variance for fluorescence cross sections is the same for all algal color groups.

Interpretation of the data presented in tables 4 and 5 can only be made after consideration is given to the magnitude and source of the uncertainties which can lead to errors in the determination of the chlorophyll a concentration contained in each algal color group.

\section{Parameters Which Can Alter Fluorescence of Chlorophyll a In Vivo}

Some of the factors which can alter the fluorescence cross section of algae include long- and short-term light history, nutrient and age effects, and water temperature (refs. 25 to 30). With the exception of the work of Campillo, Kollman, and Shapiro, who used a laser excitation source at $530 \mathrm{~nm}$, all the data presented in the following sections are from experiments where a broadband excitation source in the blue spectral region was used to excite broadband fluorescence at $685 \mathrm{~nm}$. The reported data are in terms of the ratio of algal fluorescence to chlorophyll a in vivo concentration. This ratio is proportional to the fluorescence cross section discussed previously.

Long-term light history.- Changes in fluorescence levels of chlorophyll a in vivo result from irradiation of the algae by different amounts of solar radiation. Munday and Govindjee (ref. 25) explain this phenomenon as a "membrane" reaction where different reaction centers in the cell "move" with respect to each other and thus alter the fluorescence properties of the cell. Kiefer's experiments in the Gulf of California and North Central Pacific (ref. 26) established that algal fluorescence is inversely related to solar irradiation and that this effect was limited to algae near the surface of the water. Laboratory tests were performed by Blasco (ref. 27) with the marine diatom Skeletonema costatum to determine the day/night effect on algal fluorescence. Figure 13 shows chlorophyll a concentration versus fluorescence for day and night conditions. It can be seen that the ratio of fluorescence to chlorophyll a concentration is 80 percent larger at night than during the day. Blasco conclüded that prediction of chlorophyll a concentrations from fluorescence measurements is greatly influenced by the background irradiation intensity.

Short-term light history. - The transient change in fluorescence yield of chlorophyll a in vivo during the initial few seconds of illumination has been studied by Munday and Govindjee (refs. 25 and 28). They conducted experiments into the nature of the short-term, less than $2 \mathrm{sec}$, fluorescence transient associated with the algae Chlorella. A representative fluorescence curve is given in figure 14. The algae were exposed to a 2-sec pulse of low-intensity 
light. The fluorescence yield rises instantaneously to the initial level 0. It then rises to level I in 20 to $50 \mathrm{msec}$, and remains constant or decreases slightly for a brief period before rising to the peak $\mathrm{P}$ after 0.25 to 1 sec. Within 1 to $2 \mathrm{sec}$, it decreases to the steady-state level $\mathrm{S}$. The fluorescence at $O$ is the only part of the curve which was found to be directly proportional to the intensjty of the excitation light. Unlike the other parts of the curve, it is not affected by preillumination of the algae. An additional result found by Munday and Govindjee (refs. 25 and 28) was that the time to peak $P$ is inversely proportional to the intensity of the excitation light. This has important implications for laser light excitation of algae because with highintensity illumination the fluorescence curve could go directly to $P$ without establishing 0 (private communication from Govindjee, University of Illinois, Urbana, Illinois). The qualitative shape of the curve shown in figure 14 was confirmed by E. V. Browell, O. Jarrett, Jr., F. Farmer, and C. A. Brown, Jr., using Dunaliella euchlora. A Perkin-Elmer fluorescence spectrophotometer with a flowing sample cell was used to permit exposure times greater than 2 msec for the algae. Current research into fluorescence emission of algae using picosecond laser excitation pulses has revealed that there is a decrease in the fluorescence cross section with increasing pulse intensity (ref. 30 ). Also, there is a change in this cross section if a series of picosecond excitation pulses separated by several nanoseconds are used because of changes which occur in the algae after each pulse. Thus, data obtained with excitation times shorter than a nanosecond or greater than several milliseconds are not directly applicable to flash-lamp-pumped laser excitation pulses of 300 to $500 \mathrm{nsec}$. The determination of the fluorescence nature of chlorophyll a in vivo in the submicrosecond range is very important in determining the relationship between chlorophyll a in vivo concentration and fluorescence yield for flash-lamppumped laser excitation applications.

Nutrient and age effects. - Since algae go from an exponential growth phase to a stationary growth phase as a result of exhaustion of one of the nutrients in the medium, it is primarily the limiting nutrient which causes changes in fluorescence properties of the algae. Blasco's analysis of the data obtained from investigations performed in northwestern Africa (ref. 27) showed that when a culture reaches the stationary growth phase, the ratio of fluorescence to chlorophyll a concentration increases. These results are shown in figure 15. Nicrates are directly linked to pigment formation within cells, and as a result, the ratio of fluorescence to chlorophyll a concentration increases immediately after the cells have exhausted the nitrates in the medium. Phosphate-limited cultures which were tested by Blasco did not exhibit an immediate change in fluorescence until 6 days after most of the phosphate had been depleted by the algae. In both cases the exhaustion of nutrients affects the growth of pigments and, in turn, reduces the photosynthetic activity which allows more energy to be dissipated by fluorescence. The change in the ratio of fluorescence to chlorophyll a concentration can be over 100 percent for both nitrateand phosphate-exhaustē algal cultures.

Water temperature effect.- There are conflicting reports in the literature of the influence of temperature on the fluorescence characteristics of algae. Lorenzen (ref. 29) reported a large decrease in fluorescence when the temperature of the algal medium was increased from $12^{\circ} \mathrm{C}$ to $35^{\circ} \mathrm{C}$ in a short period of time. Blasco (ref. 27) argues that the sudden change in temperature caused 
a stressed condition in the algae which caused this change in fluorescence. Laboratory results which were reported by Blasco (ref. 27) are shown in figure 16. These data were taken over a 20-minute period of time, and they exhibit a positive change in fluorescence with temperature. In contrast to these two sets of data, Kiefer (ref. 26) found, while conducting experiments in the Gulf of California, that temperature had no effect on the fluorescence of chlorophyll a in vivo. It is assumed that within naturally occurring limits, temperature is a relatively unimportant parameter in the determination of chlorophyll a in vivo fluorescence.

\section{Additional Uncertainties in the Remote Quantification of}

\section{Chlorophyll a In Vivo}

It has been assumed in the preceding derivation of the equation for the power received by a laser fluorosensor system that measurements at different excitation wavelengths are made for the same water sampling volume. Under this condition, it would be difficult to predict the effective attenuation coefficients to greater than 30-percent accuracy even if the values for the absorption and scattering coefficients were known precisely. This is because the form of the equation for the effective attenuation coefficient is only an approximation and because the attenuation coefficients vary depending upon the scattering characteristics, and the amount and vertical distribution of turbidity. If no knowledge of the scattering coefficient can be remotely obtained for the sampling volume, the uncertainty in $\gamma_{\ell}$ and $\gamma_{f}$ would be greater than 50 percent. Further, the effective attenuation coefficient at each excitation wavelength has at least a 5- to 10-percent uncertainty relative to other excitation wavelengths. If the measurements for all excitation wavelengths cannot be made for the same sampling volume, the uncertainty in the attenuation coefficients for each laser excitation becomes very large, unless the body of water is uniform in turbidity over the distance traveled during one measurement cycle.

For a field measurement of laser output power and received fluorescence power, it is assumed that a measurement accuracy of 5 percent is typical with 2.5 percent attainable.

A greater than 40-percent variation in the fluorescence cross section for various species within the same algal color group (ref. 14) can create large uncertainties in determination of the chlorophyll a in vivo concentration by the laser fluorosensor system. Some of this intragroup variation may only be in absolute magnitude, and the relative spectral characteristics may be the same. For example, an error in the measurement of chlorophyll a contained in the algae can arise because of difficulty in complete extraction of all chlorophyll a from the algal cells. Part of the uncertainty in fluorescence cross section can result from changes in the relative excitation spectra of various species within a color group. The source and nature of this cross section variation is not known; however, it is realistic to assume a 5- to 10-percent uncertainty in the relative fluorescence cross section at each excitation wavelength. 
The vertical distribution of algae can change dramatically in the first $5 \mathrm{~m}$ and the ratio of fluorescence to chlorophyll a concentration changes with depth because of different amounts of solar irradiance reaching different depths (ref. 26). In terms of the present analysis, only average values of chlorophyll a concentrations and fluorescence cross sections can be used. The errors involved in these assumptions are difficult to quantify in terms of their impact on the accuracy of chlorophyll a in vivo concentration because each measurement condition is different. The horizontal variation of algae can be very large over only a few meters, especially during bloom conditions; and with large changes in algal concentrations, large changes in the attenuation coefficients occur. For these reasons it is imperative that all measurements be made over the same sampling volume.

\section{Discussion of Error Analysis Results}

For single-wavelength laser fluorosensor systems, it can be seen from table 1 that increased measurement accuracy of output and received power from 5 to 2.5 percent does not significantly decrease the error in the chlorophyll a concentration when the error in the effective attenuation coefficient is greater than 10 percent. Without remote measurement capability for the attenuation coefficient, the error in its estimation can be large, greater than 50 percent. If the standard deviation of the effective attenuation coefficient is small, the uncertainty in the chlorophyll a concentration is nearly the same as it is for fluorescence cross section. Thus, the resulting standard deviation for chlorophyll a concentration depends primarily upon both $\delta \mathrm{k} / \mathrm{k}$ and $\delta \sigma / \sigma$.

From the fluorescence cross section data presented in reference 14 , an excitation wavelength can be selected for which the fluorescence cross sections for all four algal color groups are nearly equal. The approximate wavelength is $618 \mathrm{~nm}$. The average fluorescence cross section information at this wavelength for the color groups is given in table 2. If an average fluorescence cross section of $0.15 \times 10^{-21} \mathrm{~m}^{2}$ is assumed for any algal composition encountered with the single-wavelength laser fluorosensor system, the maximum error in the fluorescence cross section is 40 percent, and thus the standard deviation $\delta \mathrm{n} / \mathrm{n}$ would be less than 40 percent. Uncertainties in effective attenuation coefficients and fluorescence cross section due to factors listed in previous sections also influence the error in the chlorophyll a concentration, as shown in table 1. With a supplemental remote measurement of attenuation coefficients, it is felt that the concentration of chlorophyll a can be determined within 100-percent accuracy, which is sufficient for many applications.

For the multiple-wavelength laser fluorosensor to be able to determine the chlorophyll a concentration in each algal color group, the uncertainties of the fluorescence cross sections must be reduced so that the normalized standard deviation for the chlorophyll a concentration in all color groups is less than 1.0. Under these conditions, matrix equation (11) can be solved without difficulty for the concentration matrix. If $\delta \mathrm{n} / \mathrm{n}$ is greater than 1.0 for any color group due to an uncertainty in $\sigma, \sum$ is an ill-conditioned matrix, which can produce completely unrealistic values for the chlorophyll a concentrations (e.g., negative concentrations). The error analysis for multiple-wavelength 
systems was separated into two parts as a result of different statistics applied to the fluorescence cross sections. The variance relationship between $\mathrm{P}_{0}, \mathrm{P}_{r}, \mathrm{k}$, and $\mathrm{n}$ is the same in both cases. In table 4 the results are presented for the normalized standard deviation of the chlorophyll a concentration when the fluorescence cross section is considered independent of excitation wavelength. Even if the same sample volume is used for all excitation wavelengths, at least a 10-percent uncertainty in the relative excitation spectra for each of the color groups is anticipated. If different sample volumes are used during a measurement cycle, the uncertainty in the fluorescence cross section increases because of the possibility of changing algal concentrations and composition. In table 4 it can be seen that even for $\delta \sigma / \sigma=0.1$, case I had a value of $\delta n / n>1.0$. Not until $\delta \sigma / \sigma$ was greater than 0.3 did case II produce $\delta n / n>1.0$. It was explained previously that case I represented the ALOPE parameters (table 2) and case II represented the set of optimized excitation wavelengths given in table 3. Optimistic power measurement accuracies ( 2.5 percent), knowledge of relative effective attenuation coefficients at all excitation wavelengths to 5 percent, and a modest 10-percent standard deviation of fluorescence cross section produce 177-percent uncertainty in the concentration of chlorophyll a contained in the golden-brown algae when ALOPE parameters are used and only 53 percent when the optimized excitation wavelengths of case II are used. (Measurements for golden-brown algae have the most uncertainty in $\delta \mathrm{n} / \mathrm{n}$.$) In general, use of the optimized excitation wavelengths$ reduce the uncertainty in chlorophyll a concentration by a factor of 3 from the ALOPE parameters.

When the spectral variation in the fluorescence cross sections for a color group is assumed to be in a constant ratio, even though the absolute magnitude may change due to light, age, and chemical factors, the chlorophyll a concentration standard deviations given in table 5 result. As was discussed previously, the magnitude of the fluorescence cross section can vary over 100 percent by chemical stress. The ALOPE system parameters, which were used in case I, produce unacceptably high uncertainties for all the input parameters shown in the table. The optimized excitation wavelengths used in case II yield values for $\delta \mathrm{n} / \mathrm{n}$ which are less than 100 percent even for large uncertainties in the fluorescence cross sections.

The data presented in tables 4 and 5 are a result of different statistical approaches which at tempt to evaluate extreme values for the uncertainties in chlorophy II a concentrations. In both approaches, the ALOPE system parameters produced standard deviations in $n$ greater than 3 times those produced in case II, which assumed more optimized excitation wavelengths.

\section{CONCLUDING REMARKS}

Accuracy in the remote determination of chlorophyll a in vivo concentration depends upon the use of the correct equation for the power received by a laser fluorosensor system. The appropriate form of this relationship is derived in this paper (eq. (6)). Similar equations have been reported in the literature; however, they differ from the present equation by as much as a factor of 10 . 
Low-intensity long-exposure excitation of algae, which is used in fluorescence spectrophotometer studies, must be correlated with high-intensity shortpulse laser excitation of algae before spectrophotometer measurements of algal fluorescence cross sections can be used in laser fluorosensor system investigations. Also, additional research needs to be conducted on the variation of fluorescence yield which occurs in algae because of varying ambient light levels and nutrient concentrations. The uncertainties associated with these factors directly affect the accuracy of the remote chlorophyll a in vivo concentration measurements.

The use of optimized excitation wavelengths in a four-wavelength laser fluorosensor system can reduce uncertainties in the chlorophyll a concentration measurement by more than a factor of 3 from the present ALOPE (Airborne Lidar Oceanographic Probing Experiment) system. Assuming optimistic estimates of power measurement accuracies and of uncertainties in attenuation coefficients and algal fluorescence cross sections, a laser fluorosensor system with optimized excitation wavelengths would produce chlorophyll a concentration uncertainties in all four color groups of less than 53 percent.

The use of a "ground-truth" point to calibrate the laser fluorosensor system can only be used in large bodies of water where the water conditions change slowly over long distances. However, under those circumstances the variation in algal types would not be expected to change significantly, and a singlewavelength system could be used for the chlorophyll a measurement.

In water where marine conditions vary widely over short distances, supplemental remote measurements of marine attenuation coefficients and environmental factors which affect the fluorescence cross section of algae (e.g., nutrient concentration and ambient light intensity) are necessary at each sample point of the laser fluorosensor system. Without this additional measurement capability, both the single- and multiple-wavelength laser fluorosensor systems can only provide qualitative information about the chlorophyll a contained in the algae, and the single-wavelength system yields results which are comparable to a multiple-wavelength system with optimum excitation wavelengths.

Langley Research Center

National Aeronautics and Space Administration

Hampton, VA 23665

April 7, 1977 


\section{REFERENCES}

1. Clarke, George L.; Ewing, Gifford C.; and Lorenzen, Carl J.: Spectra of Backscattered Light From the Sea Obtained From Aircraft as a Measure of Chlorophyll Concentration. Science, vol. 167, no. 3921, Feb. 20, 1970, pp. 1119-1121.

2. Duntley, Seibert Q.: Detection of Ocean Chlorophyll From Earth Orbit. 4 th Annual Earth Resources Program Review. Volume IV - National Oceanic and Atmospheric Administration Programs and U.S. Naval Research Laboratory Programs, NASA TM X-68563, 1972, pp. 102-1 - 102-25.

3. Bressette, Walter E.: An Optical Filtering System for Remote Sensing of Phytoplankton and Suspended Sediment. NASA paper presented at 1974 Earth Environment and Resources Conference (Philadelphia, Pennsylvania), Sept. 1974.

4. Grew, Gary W.: Remote Detection of Chlorophyll-A in Coastal Waters. NASA paper presented at Fifth Annual Remote Sensing of Earth Resources Conference (Tullahoma, Tennessee), Mar. 1976.

5. Johnson, Robert W.: Application of Aircraft Multispectral Scanners to Quantitative Analysis and Mapping of Water Quality Parameters in the James River, Virginia. NASA paper presented at XIXth Meeting of COSPAR, Latest Results of Earth Surveys (Philadelphia, Pennsylvania), June 1976.

6. Govindjee; and Govindjee, Rajni: The Absorption of Light in Photosynthesis. Sci. American, vol. 231, no. 6, Dec. 1974, pp. 68-82.

7. Price, C: A.: Molecular Approaches to Plant Physiology. McGraw-Hill Book Co., Inc., 1970.

8. Mumola, Peter B.; Jarrett, Olin, Jr.; and Brown, Clarence A., Jr.: Multiwavelength LIDAR for Remote Sensing of Chlorophyll a in Algae and Phytoplankton. The Use of Lasers for Hydrographic Studies, Hongsuk $\mathrm{H}$. Kim and Philip T. Ryan, eds., NASA SP-375, 1975, pp. 137-145.

9. Hickman, G. Daniel; and Moore, Richard B.: Laser Induced Fluorescence in Rhodamine $B$ and Algae. Sparcom paper presented at 13th Conference on Great Lakes Research (Buffalo, New York), Mar.-Apr. 1970.

10. Friedman, E. J.; and Hickman, G. D.: Laser Induced Fluorescence in Algae: A New Technique for Remote Detection. NASA CR-62090, 1972.

11. Mumola, P. B.; and Kim, H. H.: Remote Sensing of Marine Plankton by Dye Laser Induced Fluorescence. Engineering in the Ocean Environment, IEEE, c.1972, pp. 204-207.

12. Kim, Hongsuk H.: New Algae Mapping Technique by the Use of an Airborne Laser Fluorosensor. Appl. Opt., vol. 12, no. 7, July 1973, pp. $1454-1459$. 
13. Jarrett, Olin, Jr.; Mumola, Peter B.; and Brown, Clarence A., Jr.: Four Wavelength LIDAR Applied to Determination of Chlorophyll A Concentration and Algae Color Group. Remote Sensing and Water Resources Management, Keith P. B. Thomson, Robert K. Lane, and Sandor C. Csallany, eds., American Water Resour. Assoc., c.1973, pp. 259-268.

14. Mumola, P. B.; Jarrett, Olin, Jr.; and Brown, C. A., Jr.: Multiwavelength Laser Induced Fluorescence of Algae in-vivo: A New Remote Sensing Technique. Second Joint Conference on Sensing of Environmental Pollutants, Instrum. Soc. America, c.1973, pp. 53-63.

15. Koeppen, S.H.; and Walker, R. E.: Effective Radiance Attenuation Coefficients for Underwater Imaging. Ocean Optics, Volume 64 of Proceedings of Society of Photo-Optical Instrumentation Engineers, L. F. Drummeter and L. E. Mertens, eds., c.1975, pp. 94-102.

16. Shannon, John G.: Correlation of Beam and Diffuse Attenuation Coefficients Measured in Selected Ocean Waters. Ocean Optics, Volume 64 of Proceedings of the Society of Photo-Optical Instrumentation Engineers, L. F. Drummeter and L. E. Mertens, eds., c.1975, pp. 3-11.

17. Tyler, J. E.; and Preisendorfer, R. W.: Light. Volume 1 of The Sea Physical Oceanography, M. N. Hill, ed., Interscience Publ., 1962, pp. 397-451.

18. Duntley, Seibert Q.: Light in the Sea. J. Opt. Soc. America, vol. 53, no. 2, Feb. 1963, pp. 214-233.

19. Duntley, Seibert Q.: Underwater Lighting by Submerged Lasers and Incandescent Sources. SIO Ref. 71-1 (Contract N00014-69-A-0200-6013), Visibility Lab., Univ. of California, June 1971. (Available from DDC as AD 730721.$)$

20. Gordon, Alan: Practical Approaches to Underwater Multiple-Scattering Problems. Ocean Optics, Volume 64 of Proceedings of the Society of Photo-Optical Instrumentation Engineers, L. F. Drummeter and L. E. Mertens, eds., c.1975, pp. 85-93.

21. Abramowitz, Milton; and Stegun, Irene A., eds.: Handbook of Mathematical Functions With Formulas, Graphs, and Mathematical Tables. NBS Appl. Math. Ser. 55, U.S. Dep. Commer., June 1964.

22. Clarke, George L.; and James, Harry R.: Laboratory Analysis of the Selective Absorption of Light by Sea Water. J. Opt. Soc. America, vol. 29, no. 2, Feb. 1939, pp. 43-55.

23. Hulburt, E. 0.: Optics of Distilled and Natural Water. J. Opt. Soc. America, vol. 35, no. 11, Nov. 1945, pp. 698-705.

24. Bevington, Philip R.: Data Reduction and Error Analysis for the Physical Sciences. McGraw-Hill Book Co., Inc., 1969. 
25. Munday, John C., Jr.; and Govindjee: Light-Induced Changes in the Fluorescence Yield of Chlorophyll A in Vivo. III - The Dip and the Peak in the Fluorescence Transient of Ch̄lorella pyrenoidosa. Biophys. J., vol. 9, no. 1, 1969, pp. 1-21.

26. Kiefer, D. A.: Fluorescence Properties of Natural Phytoplankton Populations. Mar. Biol., vol. 22, 1973, pp. 263-269.

27. Blasco, Dolores: Variations of the Ratio in Vivo-Fluorescence $\alpha-C h l o r o p h y l l$ and Its Application to Oceanography. Effect of Limiting Different

Nutrients, of Night and Day and Dependence on the Species Under Investigation. NASA TT F-16,317, 1975.

28. Munday, John C., Jr.; and Govindjee: Light-Induced Changes in the Fluorescence Yield of Chlorophyll A in Vivo. IV - The Effect of Preillumination on the Fluorescence Transient of Chlorella pyrenoidosa. Biophys. J., vol. 9, no. 1, 1969, pp. 22-35.

29. Lorenzen, Carl J.: A Method for the Continuous Measurement of in vivo Chlorophyll Concentrations. Deep-Sea Res. \& Oceanogr. Abstr., vol. 13, 1966, pp. 223-227.

30. Campillo, A. J.; Kollman, V. H.; and Shapiro, S. L.: Intensity Dependence of the Fluorescence Lifetime of in vivo Chlorophyll Excited by a Picosecond Light Pulse. Science, vol. 193, no. 4249, July 16, 1976, pp. $227-229$. 
TABLE 1.- NORMALIZED STANDARD DEVIATION OF PARAMETERS IN SINGLE-WAVELENGTH LASER FLUOROSENSOR ERROR ANALYSIS

\begin{tabular}{|l|l|l|l|l|}
\hline$\delta \mathrm{P}_{\mathrm{O}} / \mathrm{P}_{\mathrm{O}}$ & $\delta \mathrm{P}_{\mathrm{r}} / \mathrm{P}_{\mathrm{r}}$ & $\delta \mathrm{k} / \mathrm{k}$ & $\delta \sigma / \sigma$ & ${ }^{\mathrm{a}} \delta \mathrm{n} / \mathrm{n}$ \\
\hline 0.05 & 0.05 & 0.1 & 0 & 0.12 \\
.025 & .025 & .1 & 0 & .11 \\
.025 & .025 & .1 & .3 & .32 \\
.025 & .025 & .1 & .7 & .71 \\
.025 & .025 & .1 & 1.0 & 1.01 \\
.025 & .025 & .3 & 0 & .30 \\
.025 & .025 & .3 & .3 & .43 \\
.025 & .025 & .3 & .7 & .76 \\
.025 & .025 & .3 & 1.0 & 1.04 \\
.025 & .025 & .5 & 0 & .50 \\
.025 & .025 & .5 & .3 & .58 \\
.025 & .025 & .5 & .7 & .86 \\
.025 & .025 & .5 & 1.0 & 1.12 \\
\hline
\end{tabular}

acalculated from equation (13). 
TABLE 2.- ALGAL FLUORESCENCE CROSS SECTIONS FOR ALOPE SYSTEMa

\begin{tabular}{|l|c|c|c|c|}
\hline \multirow{2}{*}{$\begin{array}{c}\text { Algal } \\
\text { color } \\
\text { group }\end{array}$} & \multicolumn{4}{|c|}{$\begin{array}{c}\text { Fluorescence cross section, } \mathrm{m}^{2} \text {, at } \\
\text { excitation wavelength, nm, of - }\end{array}$} \\
\cline { 2 - 5 } & 454.4 & 539.0 & 598.7 & 617.8 \\
\hline Green & $1.152 \times 10^{-21}$ & $0.139 \times 10^{-21}$ & $0.164 \times 10^{-21}$ & $0.232 \times 10^{-21}$ \\
Golden-brown & .653 & .151 & .081 & .110 \\
Red & .133 & .450 & .447 & .255 \\
Blue-green & .071 & .050 & .152 & .239 \\
\hline
\end{tabular}

aFrom reference 14

TABLE 3.- OPTIMIZED FLUORESCENCE CROSS SECTIONS FOR FOUR-WAVELENGTH LASER FLUOROSENSOR SYSTEM

\begin{tabular}{|l|c|c|c|c|}
\hline \multirow{2}{*}{$\begin{array}{c}\text { Algal } \\
\text { color } \\
\text { group }\end{array}$} & \multicolumn{4}{|c|}{$\begin{array}{c}\text { Fluorescence cross section, m2, at } \\
\text { excitation wavelength, nm, of - }\end{array}$} \\
\cline { 2 - 5 } & 482 & 520 & 562 & 640 \\
\hline Green & $1.13 \times 10^{-21}$ & $0.28 \times 10^{-21}$ & $0.16 \times 10^{-21}$ & $0.39 \times 10^{-21}$ \\
Golden-brown & .42 \\
Red & .09 & .28 \\
Blue-green & .03 & .22 & .64 & .10 \\
.03 & .06 & .60 \\
\hline
\end{tabular}




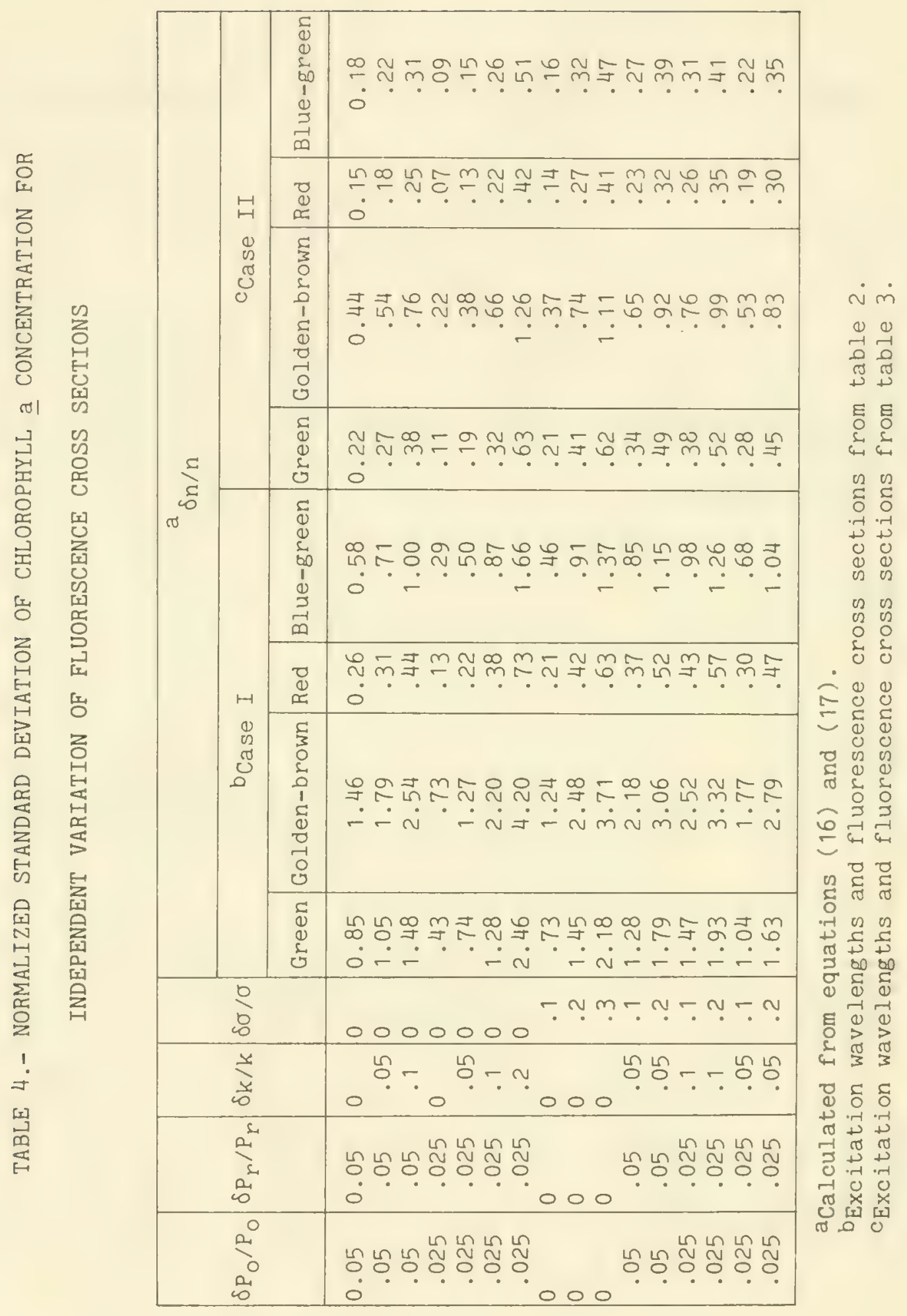




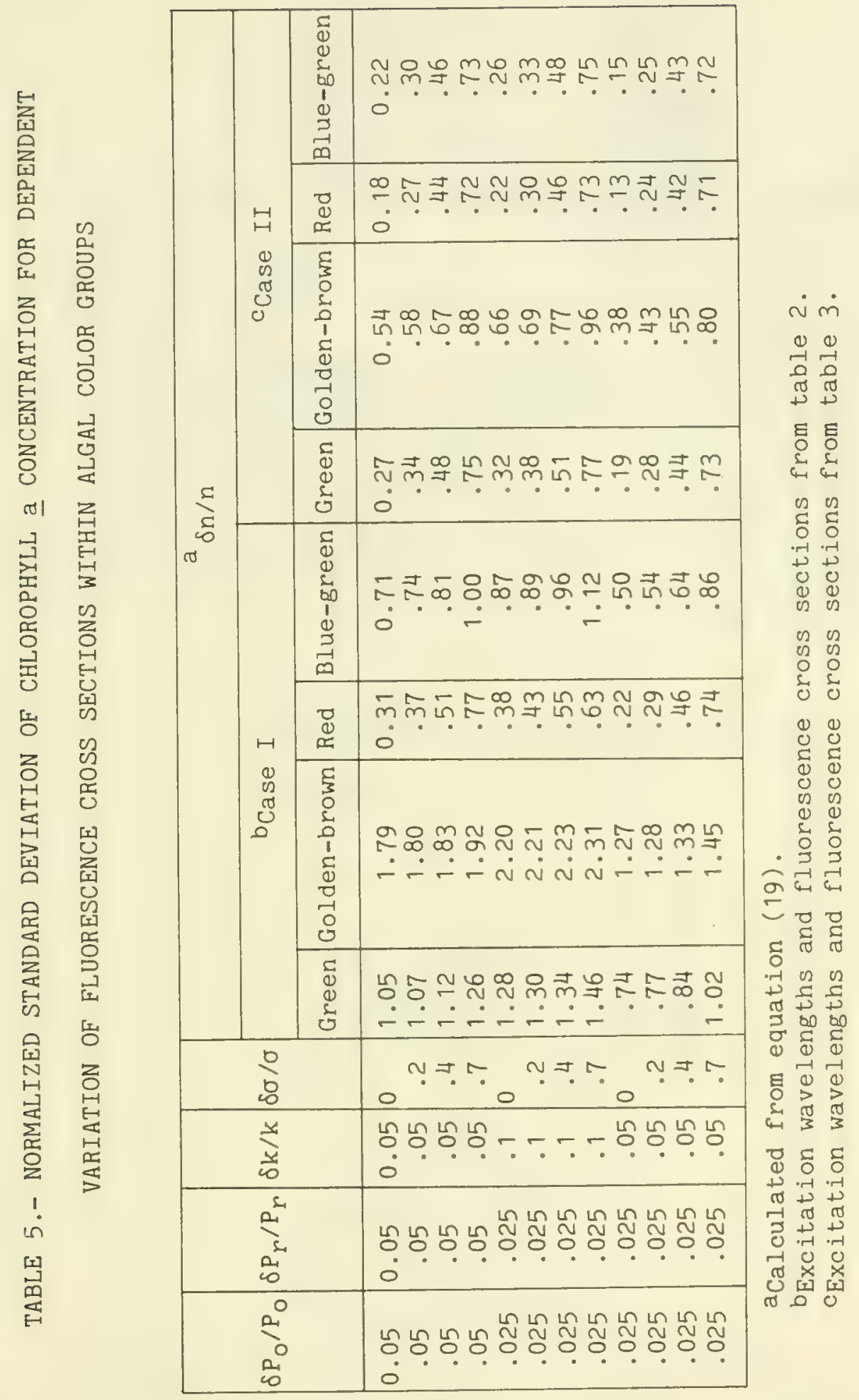




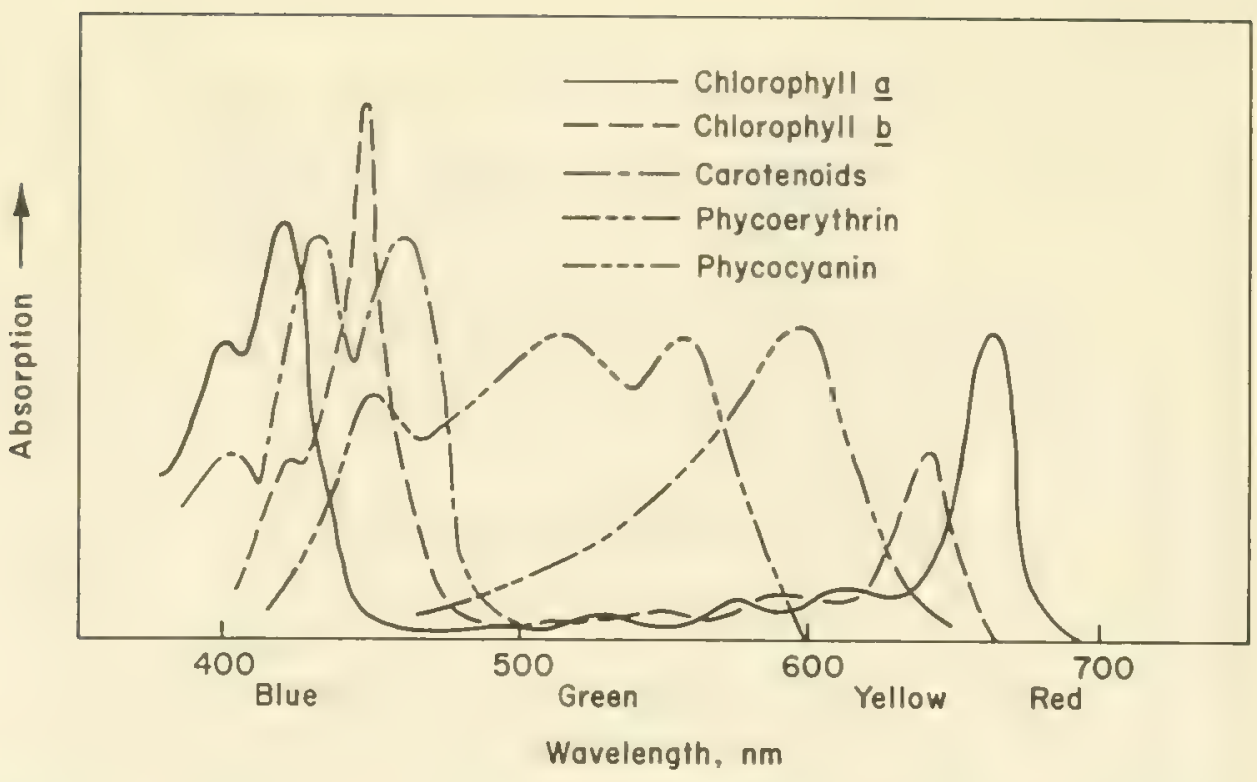

Figure 1.- Absorption spectra of pigments found in living algae. (Adapted from The Absorption of Light in Photosynthesis by Govindjee and Rajni Govindjee, Copyright (C) 1974 by Scientific American, Inc. All rights reserved.)

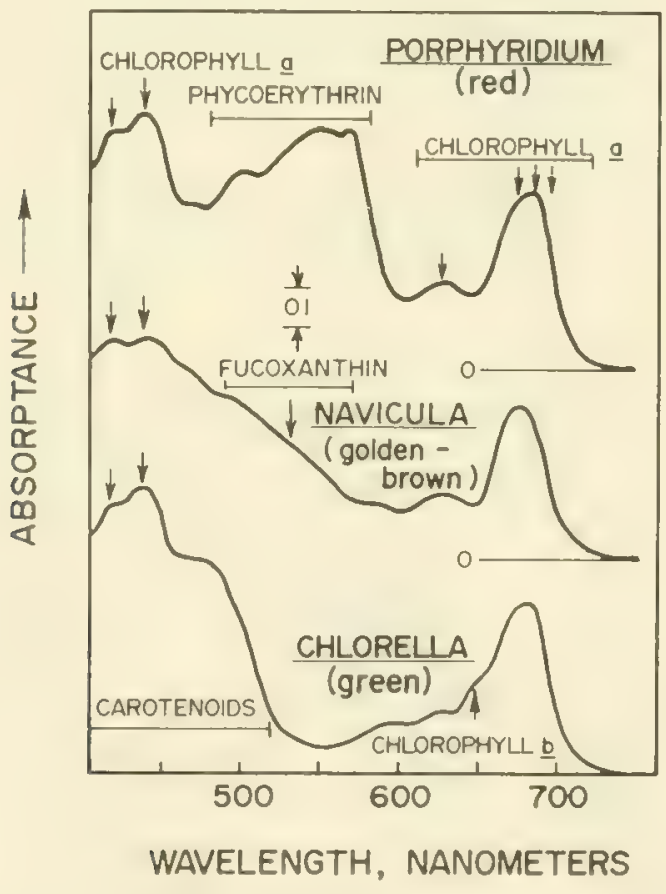

Figure 2.- Absorptance spectra of three algal species which are representative of different color groups. Algal pigments which dominate light absorption are indicated. (From Molecular Approaches to Plant Physiology by C. A. Price, c.1970, McGrawHill Book Co., Inc. with permission of publisher.) 


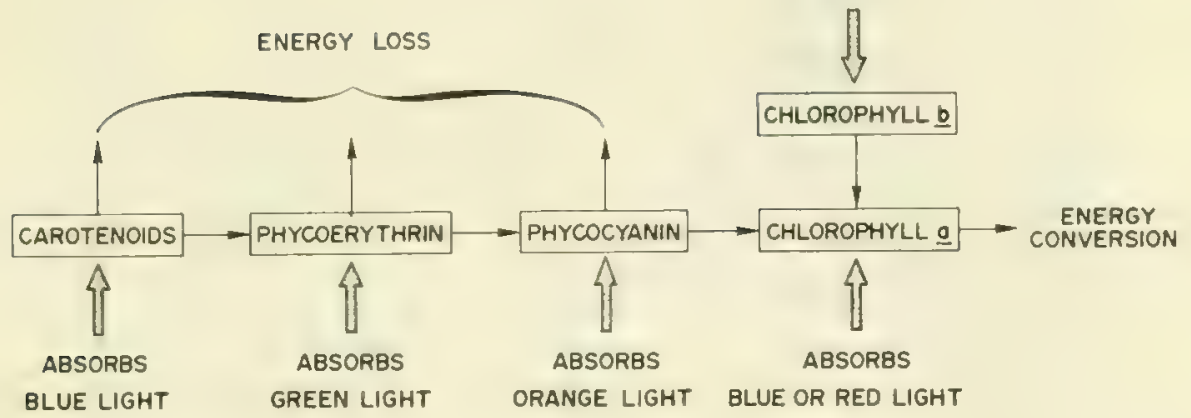

Figure 3.- Light absorption by pigments contained in living algae and path of energy transfer within algal cell. (Adapted from The Absorption of Light in Photosynthesis by Govindjee and Rajni Govindjee, Copyright (C) 1974 by Scientific American, Inc. All rights reserved.)

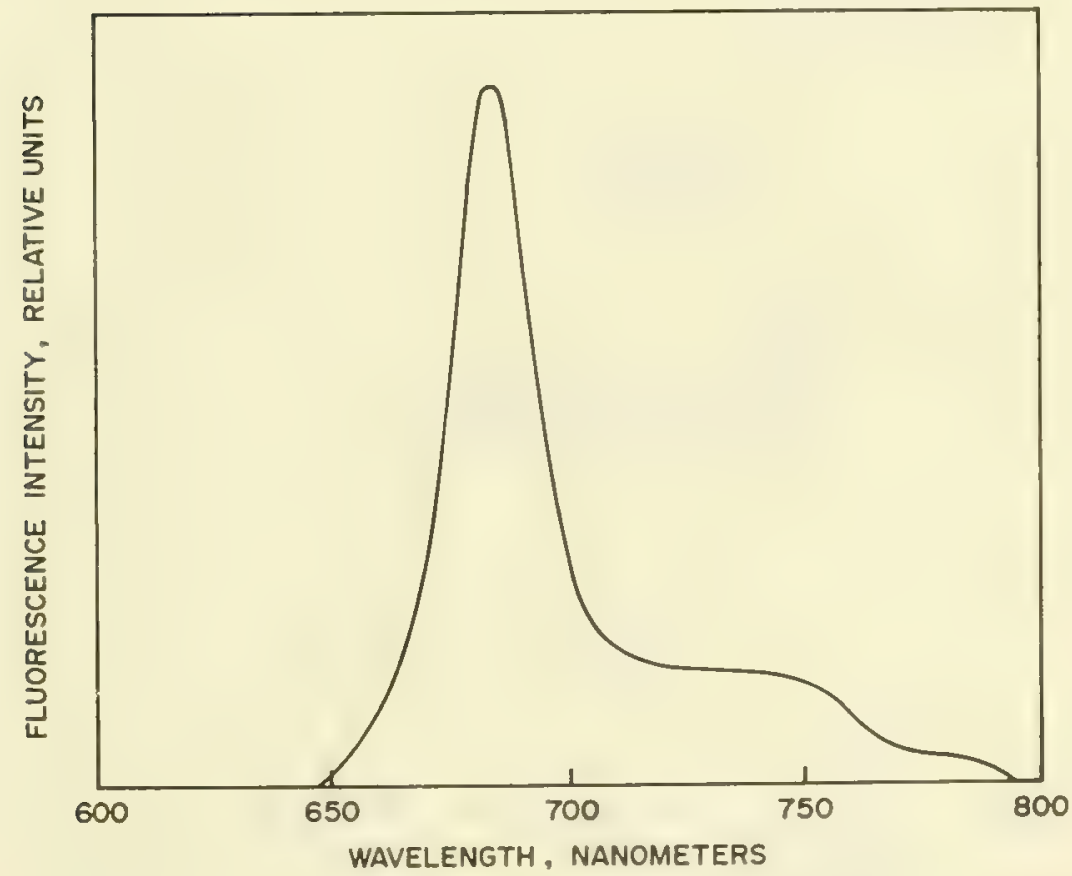

Figure 4.- Typical fluorescence spectrum for green and golden-brown algae. 


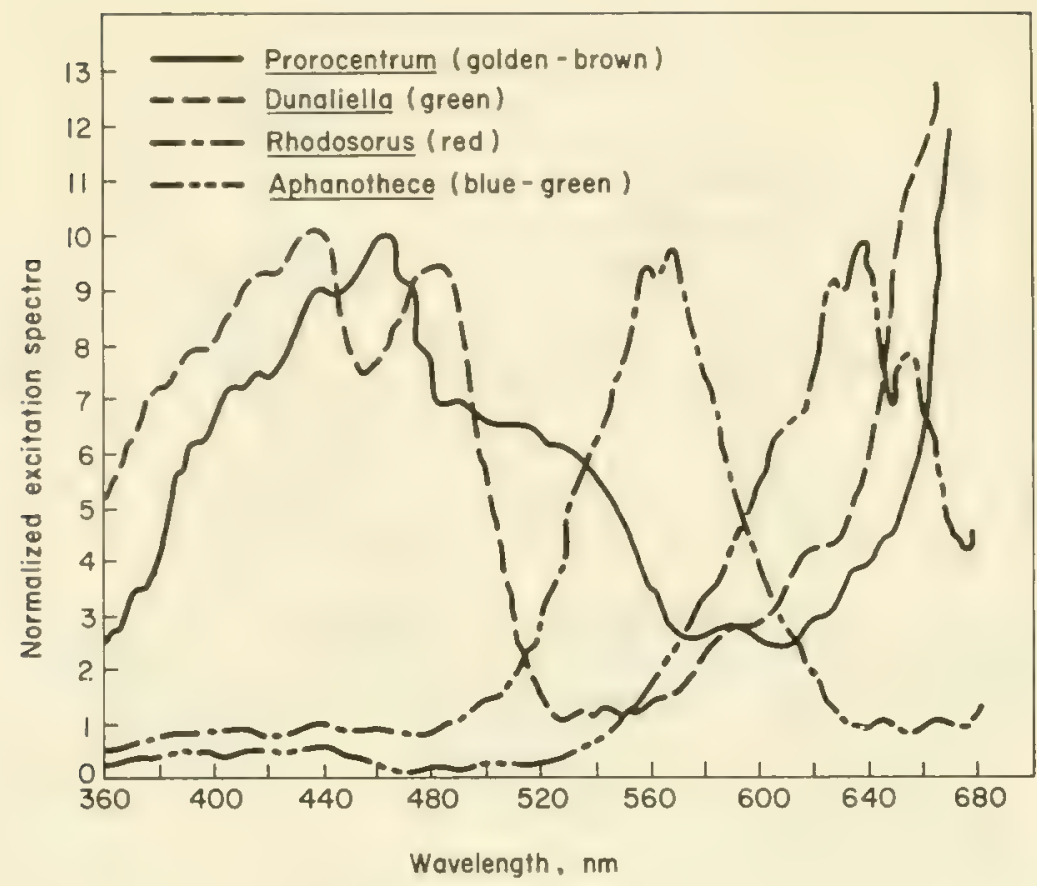

Figure 5.- Normalized excitation spectra for representative algal species from four algal color groups. Fluorescence emission at $685 \mathrm{~nm}$ was detected while excitation wavelength was changed. (Adapted from ref. 8.)

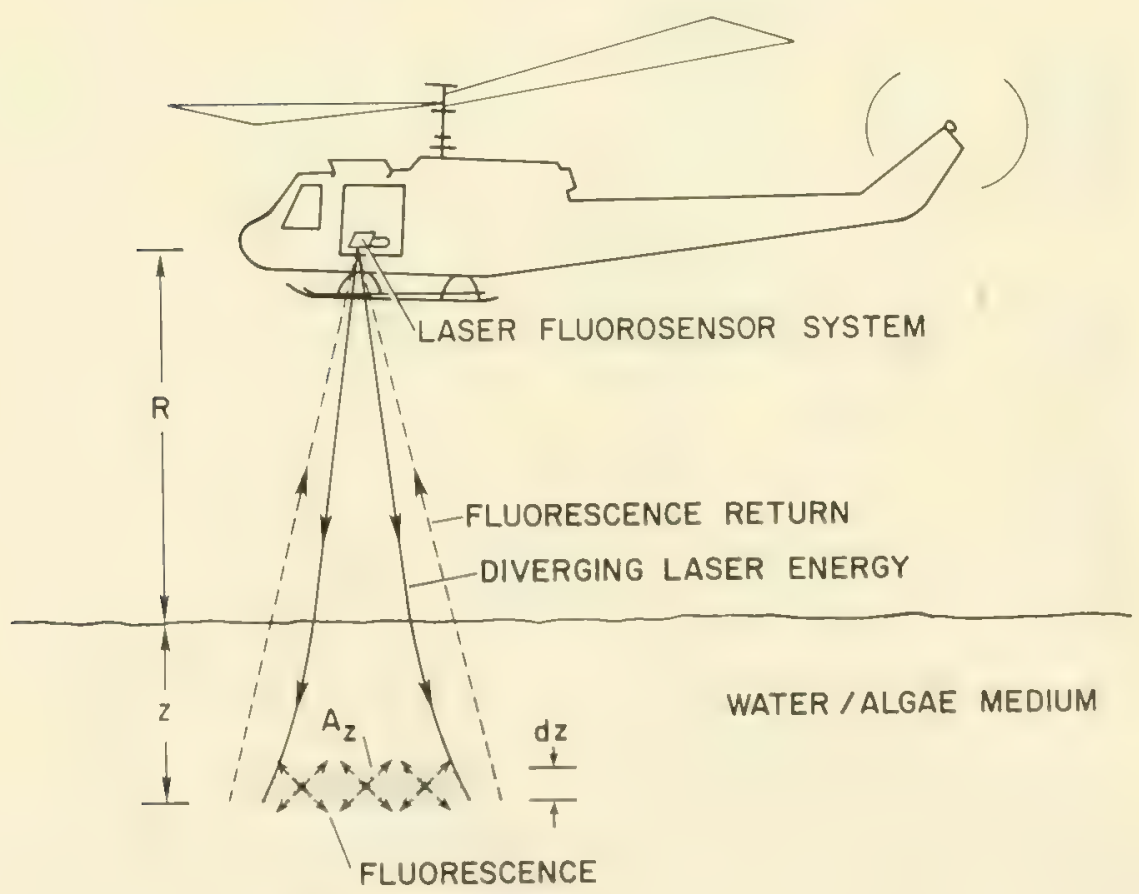

Figure 6.- Diagram used in derivation of equation for power received by a laser fluorosensor system. 


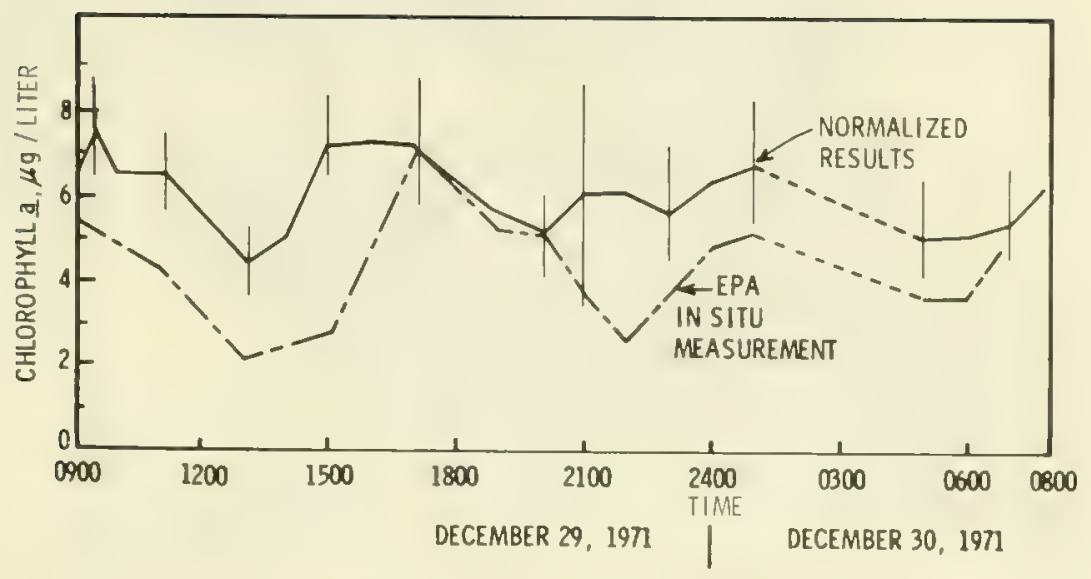

Figure 7.- Chlorophyll a in vivo concentrations determined by single-wavelength laser system from Thimble Shoals Channel Pier of Chesapeake Bay Bridge Tunnel and normalized to in situ measurements at 2000 EST on December 29, 1971. (From ref. 11.)

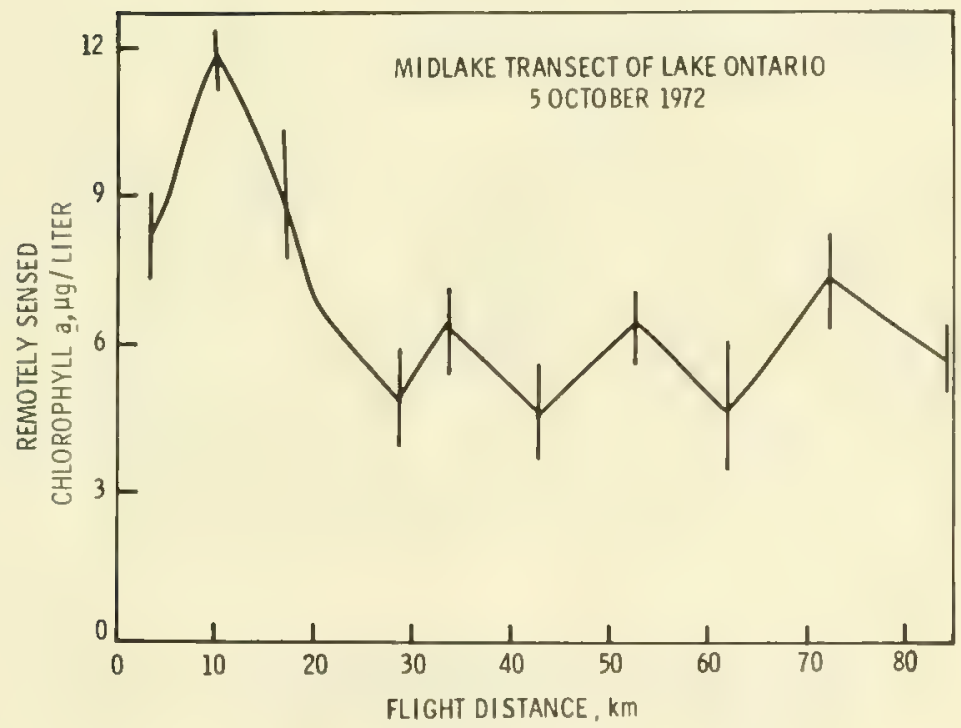

Figure 8.- Chlorophyll a in vivo concentrations measured by airborne laser fluorosensor system which was flown from west of Rochester, New York, to Canadian shore. (Adapted from ref. 12.) 


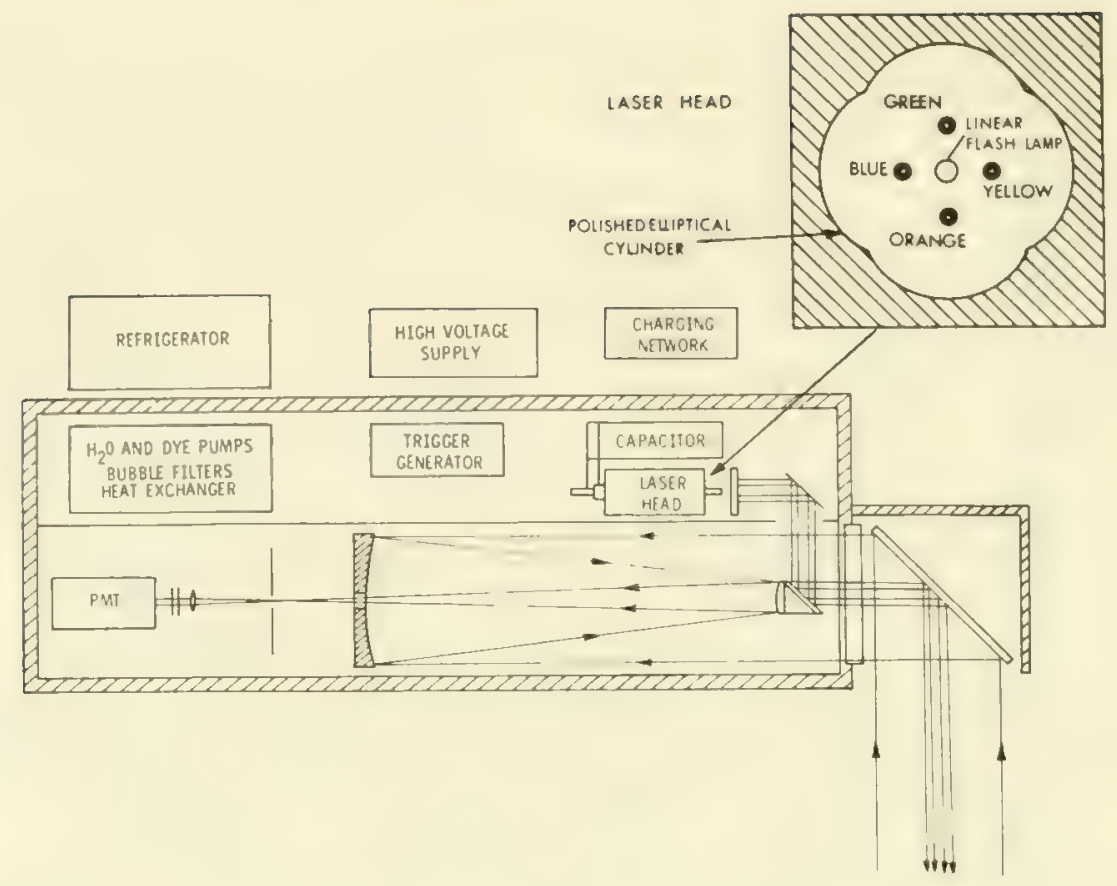

Figure 9.- ALOPE system with four-wavelength laser head (only one laser wavelength is emitted at a time), 25.4-cm-diameter receiving telescope, and associated equipment. (Adapted from ref. 13.)

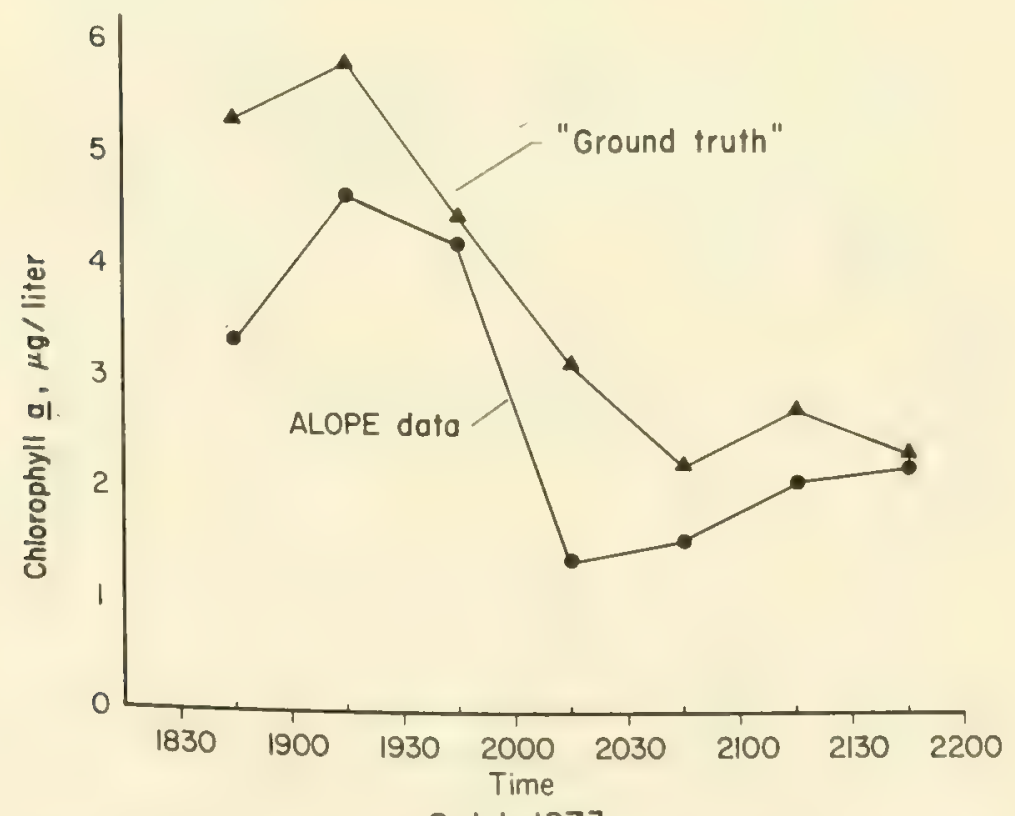

9 July 1973

Figure 10.- Chlorophyll a in vivo concentrations obtained by ALOPE system from George P. Coleman Bridge, which is $30 \mathrm{~m}$ above York River. Blue $(454 \mathrm{~nm})$ and green $(539 \mathrm{~nm})$ wavelengths only were used in data reduction. (From ref. 8.) 


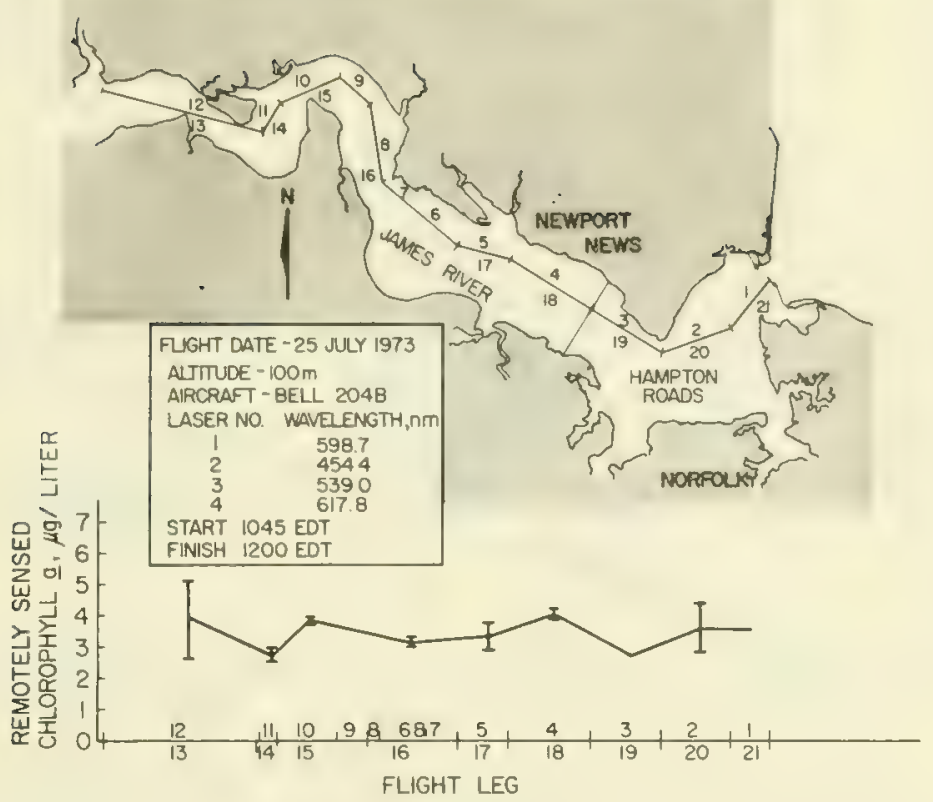

Figure 11.- Total chlorophyll a in vivo concentrations measured by ALOPE system on flight over James River. Red (598 nm) wavelength was not used in data reduction. (Adapted from ref. 8.)

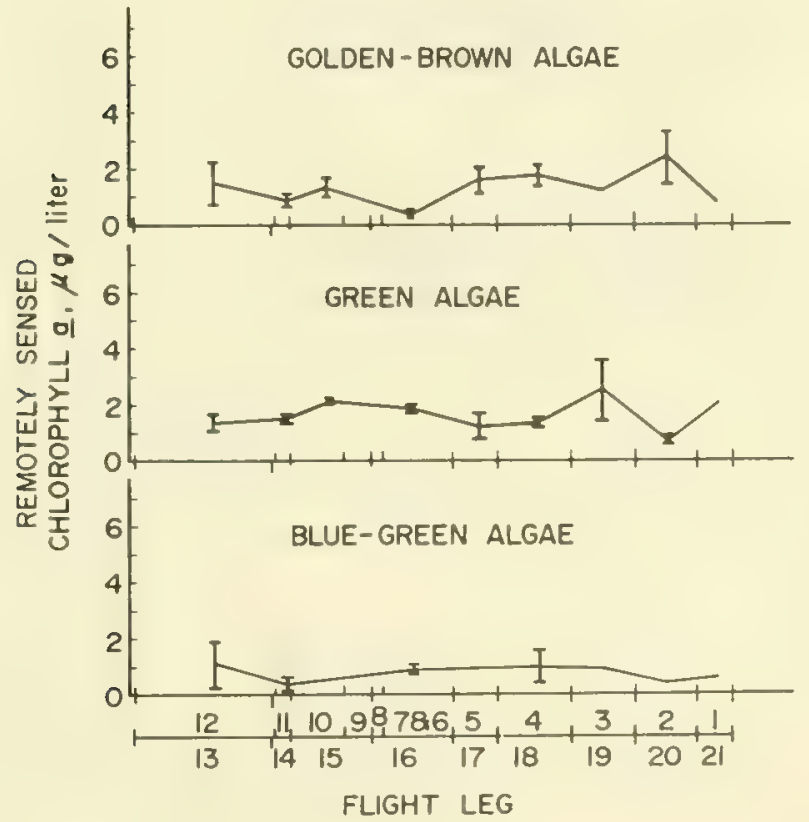

Figure 12.- Chlorophyll a contained in algal color groups as measured by ALOPE system on flight over James River. Concentrations of red algae were not determined. (Adapted from ref. 8.) 


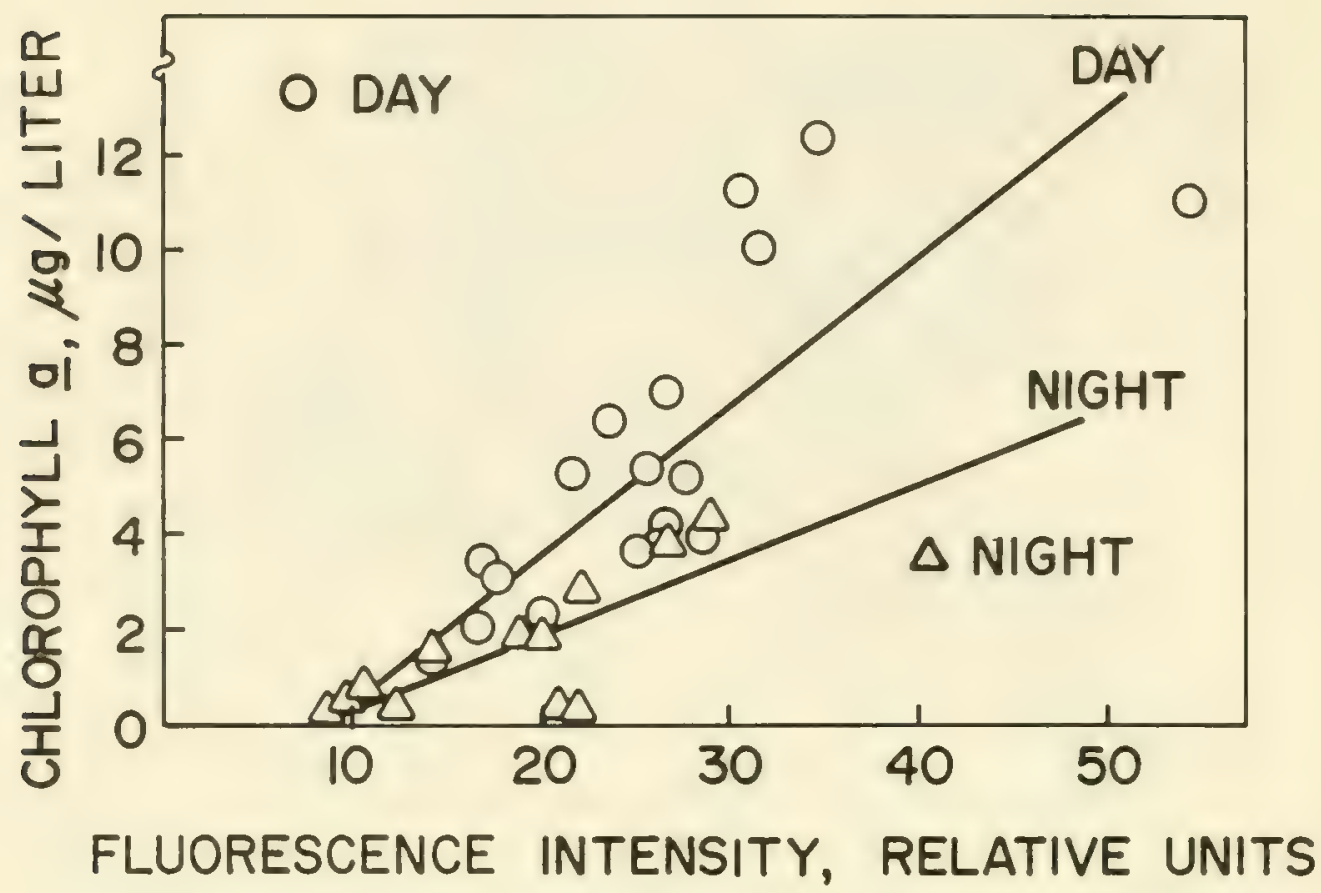

Figure 13.- Relationship between chlorophyll a concentration and fluorescence intensity for algae tested during day and night conditions. (Adapted from ref. 27.)

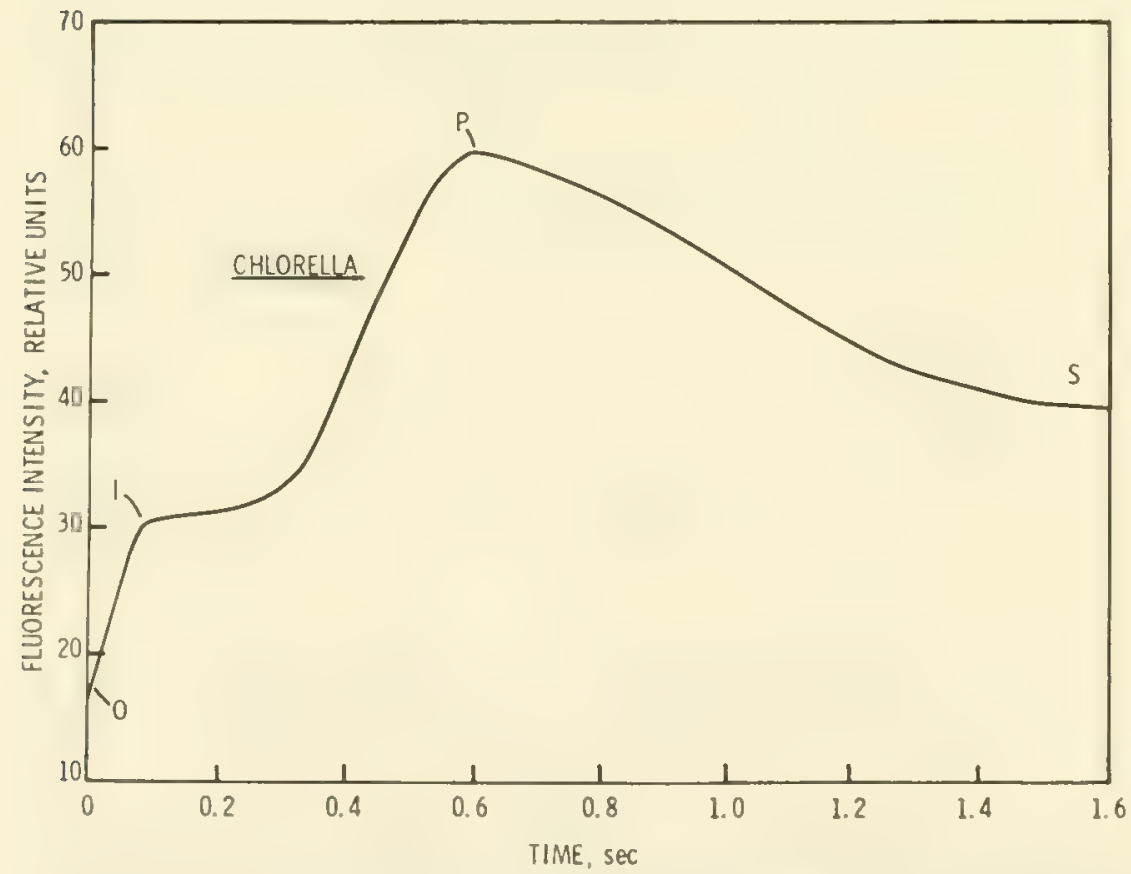

Figure 14.- Transient fluorescence curve for Chlorella when it is excited by $2-s e c$ pulse of low-intensity light. (Adapted from ref. 25.) 


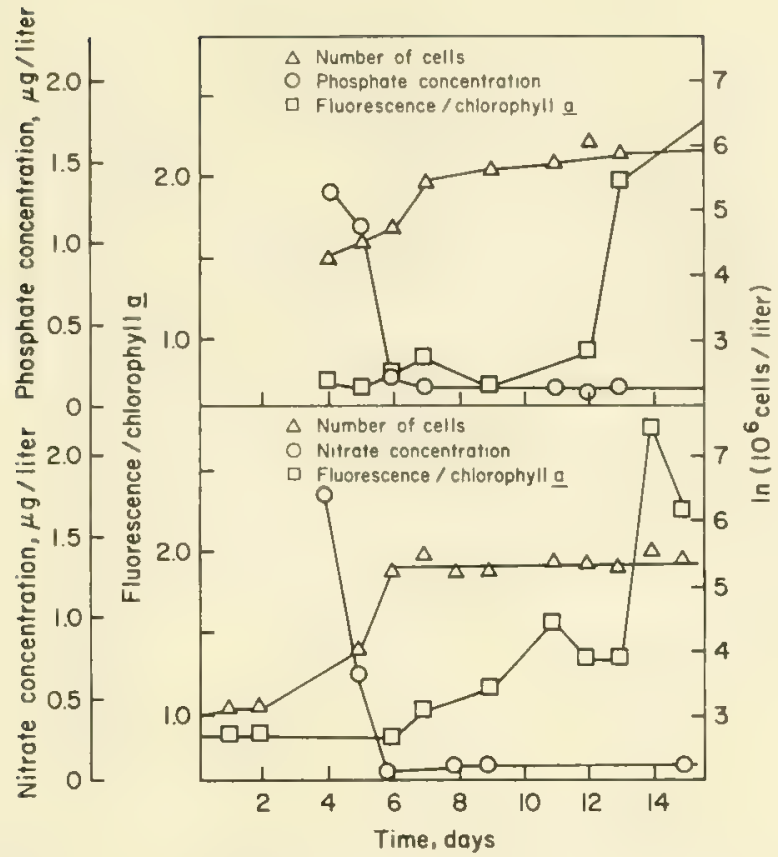

Figure 15.- Algal cell concentrations and fluorescence/chlorophyll a ratio as a function of phosphate and nitrate levels in algal growth medium. (Adapted from ref. 27. )

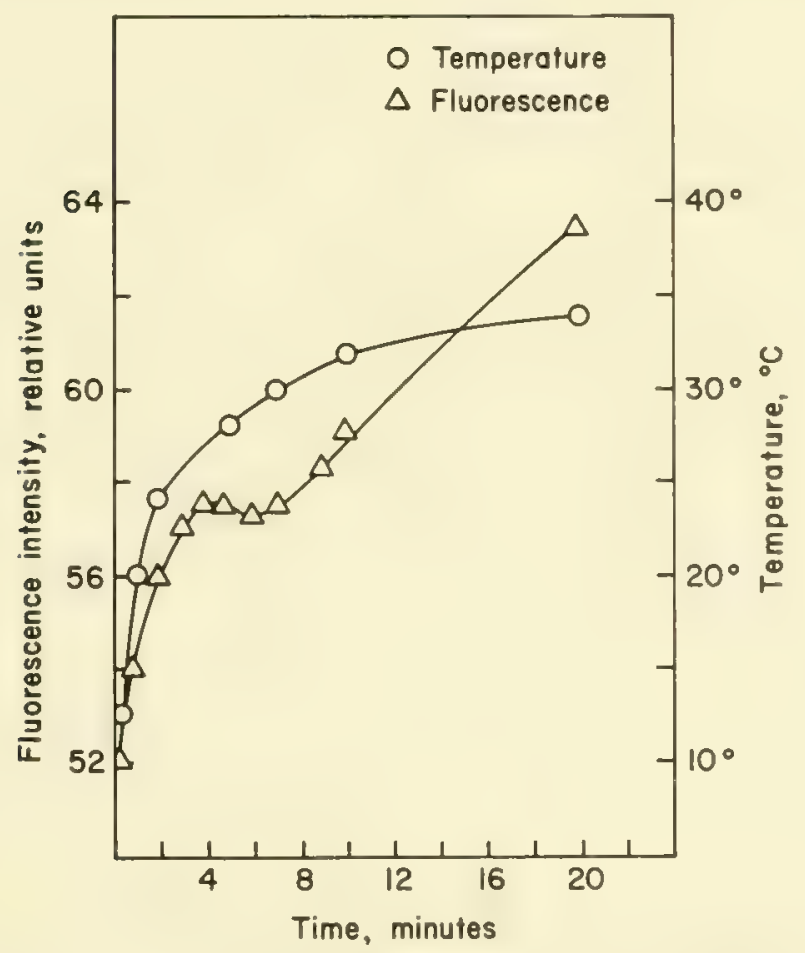

Figure 16.- Relationship between temperature and algal fluorescence. (Adapted from ref. 27. ) 







"The aeronautical and space activities of the United States shall be conducted so as to contribute ... to the expansion of human knowledge of phenomena in the atmosphere and space. The Administration shall provide for the widest practicable and appropriate dissemination of information concerning its activities and the results thereof."

- National Aeronautics and Space Act of 1958

\section{NASA SCIENTIFIC AND TECHNICAL PUBLICATIONS}

TECHNICAL REPORTS: Scientific and technical information considered important, complete, and a lasting contribution to existing knowledge.

TECHNICAL NOTES: Infornteren less broad in scope but nevertheless of inportance as a contribution to existing knowrese.

\section{TECHNICAL MEMORANDS:}

Information receiving limite $\mathbf{C}$ strib

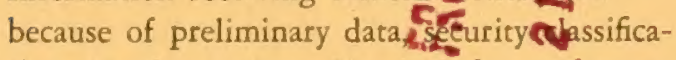
tion, or other reasons. Also includes conference proceedings with either limteg or vimited distribution.

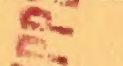

CONTRACTOR REPORTS Scientific and technical information generated under a NASA contract or grant and considered an important contribution to existing knowledge.
TECHNICAL TRANSLATIONS: Information published in a foreign language considered to merit NASA distribution in English.

SPECIAL PUBLICATIONS: Information derived from or of value to NASA activities. Publications include final reports of major projects, monographs, data compilations, handbooks, sourcebooks, and special bibliographies.

\section{TECHNOLOGY UTILIZATION}

PUBLICATIONS: Information on technology used by NASA that may be of particular interest in commercial and other non-aerospace applications. Publications include Tech Briefs, Technology Utilization Reports and Technology Surveys.

Details on the availability of these publications may be obtained from:

SCIENTIFIC AND TECHNICAL INFORMATION OFFICE 